\title{
Las concepciones sobre el progreso y la construcción de un proyecto de nación: hacia una historia de las ideas en el extendido siglo XIX mexicano (1821-1910)
}

\section{Concepts of progress and the construction of a national project: towards a history of ideas in Mexico's extended 19th century (1821-1910)}

ISAAC ENRÍQUEZ PÉREZ

Universidad Nacional Autónoma de México isaacep@unam.mx

\section{RESUMEN}

El presente artículo, más allá de los tajantes y desgastados rótulos que dividieron a las sociedades decimonónicas que parieron su independencia politica en América Latina, tiene como objetivo central brindar un panorama general en torno a las concepciones sobre el progreso difundidas en México entre 1821 y 1910, enfatizando en la recepción, reelaboración, difusión e incidencia pública de esta noción, no sin analizar - brevemente- la historia económica de la época en cuestión y el impacto de las estrategias de politica inspiradas por estas concepciones. A lo largo del manuscrito, son rastreadas las posiciones y posturas de distintos pensadores e ideólogos respecto al papel y funciones del Estado en la construcción de mercados y en la distribución de la riqueza, procurando una arqueología del pensamiento que desentrañe la transformación de la historia de las ideas mexicanas expuestas al calor del devenir convulso del siglo XIX y principios del siglo XX; las cuales lograron configurar la identidad del Estado- 
nación y arraigaron los cimientos del capitalismo a partir de la incidencia del liberalismo en sus distintas vertientes y del entramado institucional también inspirado en dicha ideología.

Palabras clave: Progreso, formación del Estado, nacionalismo liberal, librecambio/proteccionismo, industrialización.

\section{ABSTRACT}

The present article seeks to go beyond the well-worn, one-dimensional labels that divided nineteenth century societies of the independence period, providing instead an overview of the concepts of progress that spread through Mexico between 1821 and 1910, emphasizing the reception, re-elaboration, dissemination and public impact of this notion, not without briefly analyzing the economic history of the period and the effects of the policies inspired by them. The text traces the positions and stances of various thinkers and ideologists vis-à-vis the role and functions of the State in the construction of markets and distribution of wealth, seeking an archeology of thought that gets to the bottom of the transformation of the history of Mexican ideas exposed to the heat of the convolutions of the nineteenth and early twentieth century, while successfully shaping the identity of the nation-state and laying the foundations of capitalism on the basis of the influence of various trends of liberalism and the institutional framework inspired by this ideology. Keywords: Progress, state formation, liberal nationalism, free trade/protectionism, industrialization. 
El surgimiento y expansión del capitalismo, la misma revolución industrial inglesa, los movimientos intelectuales como la Ilustración, el despliegue de la llamada modernidad europea y el difusionismo de estas expresiones en el mundo fueron acontecimientos preńados de la seductora idea de progreso. Esto es, el razonamiento de que la humanidad avanza lineal, continua y gradualmente desde una situación primitiva hacia niveles o estadios superiores y de perfección tanto intelectual y moral como económicamente. Esta noción se arraigó fuertemente entre 1750 y 1900 en el ideario de las sociedades europeas y de aquellas que recibieron su influencia directa e indirectamente. En el siglo XIX, el mismo Herbert Spencer (1820-1903) sentenció que el progreso no es un accidente, ni nada bajo el control del hombre, sino una necesidad beneficiosa que forma parte de la naturaleza. ${ }^{1}$ Durante los siglos XVIII y XIX, se asumió que el progreso va de la mano del crecimiento económico; incluso, algunos pensadores argumentaron que el comercio, la libertad y el progreso se encuentran íntimamente relacionados. ${ }^{2}$

Si partimos de la afirmación hecha por Robert Nisbet — de que la fe en el progreso es la tendencia dominante a lo largo de la historia ${ }^{3}$ resulta importante preguntarnos cómo se configura y entreteje esta idea en el convulsionado México del siglo XIX; fundamentalmente, en dos de sus principales expresiones: por un lado, las estrategias que en determinadas circunstancias económicas y sociopolíticas concibieron como necesarias para trascender o avanzar — según se argumentó — a estadios superiores de organización productiva; y por otro, el papel que se le atribuye en estas concepciones sobre el progreso al Estado en el proceso económico.

En los esfuerzos mexicanos por construir un proyecto nacional durante el siglo XIX y los primeros años del siglo XX, se encuentra fuertemente arraigada la idea de progreso. Sea para abolir el orden socioeconómico colonial, o para emprender un proceso de incipiente modernización, la idea de progreso se presenta como el referente conceptual en torno al

1 Spencer 1851.

2 Nisbet 1981: 251.

3 Ib.: 19. 
cual se desplegaron distintas perspectivas, corrientes de pensamiento y grupos sociales que las adoptaron.

El conocer e interpretar los postulados y la relevancia de estas corrientes de pensamiento resulta crucial para situar su dimensión histórica y su influencia en la configuración de un proyecto de nación que le diese salida y cauce a la caótica situación de la sociedad mexicana y su proceso económico. A riesgo de equivocarnos, planteamos hipotéticamente que las corrientes de pensamiento más influyentes durante el siglo XIX —el liberalismo y el positivismo- lograron plantear una idea de progreso que con mucho se distanció de la ideología y el orden coloniales, así como de los grupos hegemónicos que los impulsaron. Sin embargo, estas corrientes de pensamiento no estuvieron exentas de pugnas ideológico/ políticas; más bien, se vieron envueltas en un conflicto que solo fue superado con la restauración de la República y con el ascenso al poder de la élite encabezada por el general Porfirio Díaz.

Rastrear brevemente las concepciones sobre el progreso planteadas en México entre 1821 y 1910 implica formularnos los siguientes interrogantes: ¿Cuáles son las corrientes de pensamiento que participaron en torno al debate de la idea de progreso, y en qué consistían sus principales planteamientos? ¿Cuáles fueron, durante este periodo, sus propuestas normativas más destacadas, y de qué manera influyeron en la formación y expansión del Estado-nación mexicano? ¿El progreso se abordó de manera integral o solo se reducía a su vertiente económica en detrimento de lo social, lo cultural y lo político?

En suma, partiendo de estas preguntas, nuestros objetivos de investigación consistieron en interpretar los cambios en las concepciones sobre la idea de progreso con base en los planteamientos de las corrientes filosóficas y del pensamiento económico, rescatando el contexto histórico en el cual se gestan, así como las fuerzas y actores sociales que las postulan o las adoptan. Se trata, más que nada, de una mirada a vuelo de pájaro sobre las estrategias propuestas en México durante el siglo XIX en torno a la estructuración de la economía y la modelación de la sociedad; todo lo cual fue medular en la construcción de un proyecto de nación en medio de la característica inestabilidad sociopolítica de esas décadas. 
A grandes rasgos, lo que nos propusimos fue desentrañar los aportes, alcances y limitaciones de la idea de progreso y la vertebración de la acción social que se dio a partir de sus propuestas de política.

Una premisa resultó fundamental durante el ejercicio de la investigación que respalda el presente artículo, a saber: a lo largo del siglo XIX y la primera década del siglo XX, la historia de las ideas en México asimila — no siempre de manera creativa - la noción de progreso con el fin último de cimentar y legitimar el arraigo y profundización del capitalismo, sus relaciones sociales de producción, las instituciones y los códigos y simbolismos que les son consustanciales; al tiempo que se definió con dicha noción el perfil, los rasgos e identidad del Estado procreado en medio de la decimonónica convulsión social y política. No menos importante fue el hecho de que las concepciones sobre el progreso mostraron una veta evidentemente ideológica que insufló sensaciones de ilusión en el marco de estos procesos económicos y políticos que, en largos lapsos, mantuvieron postrada a la novel nación. Aunque existieron rupturas y continuidades en la línea del tiempo de este pensamiento, cabe destacar que subyacen ciertos paralelismos con la llamada era del desarrollo que irradió en México hasta caer su crepúsculo hacia la década de los ochenta del siglo XX. ${ }^{4}$

\section{LA NOCIÓN DEL CONCEPTO DE PROGRESO A TRAVÉS DE LA HISTORIA DE LA HUMANIDAD}

El supuesto de que las sociedades transitan por estadios sucesivos que levantan su vuelo desde el pasado distante, la ignorancia, la barbarie y el atraso hasta alcanzar - a futuro- la plenitud, el conocimiento y la mejora de las condiciones de vida o el perfeccionamiento de la humanidad, se remonta a la antigüedad europea y se erige en el principal eslabón del discurso ideológico que sustenta a la civilización capitalista. Bajo la premisa del cambio social, la perfectibilidad y la inevitabilidad histórica, a lo largo de 2500 años fue entronizada la fe en la noción

4 Sobre esta etapa y la ideología del nacionalismo revolucionario, véase Enríquez Pérez 2016 . 
de progreso; sin embargo, más allá de este manto seductor e ilusionista, el progreso conforma - a partir de sus dosis de juicios de valor- el andamiaje simbólico de la praxis científica y de las concepciones de corte teleológico. Por una parte, el progreso fue concebido como el avance o perfeccionamiento gradual de los conocimientos y saberes que permiten al ser humano encontrar respuestas y soluciones para vivir en colectividad y domesticar la naturaleza; por otro lado, ciertas concepciones lo remiten a la felicidad terrenal y a la mejora del espíritu para enfrentar con calma el agobio de la naturaleza y la sociedad. ${ }^{5}$ El mismo Nisbet identifica varios pilares que, históricamente, conforman la idea de progreso; a saber: a) la valoración del pasado (y la consecuente distinción pasado/ presente/futuro); b) la convicción de que la civilización occidental es noble, excepcional y superior a otras; c) la aceptación del crecimiento económico y el cambio tecnológico; d) la fe en la razón y la ciencia; y e) la valoración y defensa de la vida como valor supremo en el universo. ${ }^{6}$

Con el movimiento filosófico de la modernidad europea, el progreso fue concebido como una creación humana, fruto de su acción social para imponerse a la naturaleza todopoderosa explicada y regida por las deidades antiguas que, finalmente, fueron suplantadas por el reinado libertario e igualitario del continuo perfeccionamiento humano. En tanto nuevo espíritu de esta modernidad, el progreso fue asumido como la culminación del sendero teleológico introducido por los judíos e interiorizado por los cristianos para encaminar a las sociedades hacia un fin determinado: la salvación como progreso regresivo que marcha a la decadencia desde el pecado original y la previa inocencia en el paraíso; y — según los designios de la Providencia - alcanzar un futuro colmado de gloria a través de la salvación eterna.

Bajo los supuestos del excepcionalismo europeo y la noción de la historia como una larga e inevitable marcha unilineal de la humanidad hacia la perfección en la tierra, el progreso se erigió en un axioma dogmático que no precisó de contrastación empírica, sino que fungió,

5 Nisbet 1981 .

6 Ib.: 438. 
más bien, como un simple manto religioso que envuelve las conciencias de quienes extienden su fe en un juicio de valor sobre el rumbo y devenir de la historia. Cabe destacar, que esta creencia tiende a eclipsarse con la dificultad de medir al progreso empíricamente y con las mismas dudas que suscita el hecho de que las sociedades no siempre marcharon hacia adelante, pues su camino fue obstruido en los últimos dos siglos por las montañas del totalitarismo, el racismo, la guerra y las crisis económico/ financieras. Sin embargo, en tanto directriz rectora dotada de universalismo y del supuesto orden natural de los hechos, la noción de progreso incentiva en el ser humano la creatividad para emprender grandes proezas y nutre la esperanza y la confianza de las sociedades y los individuos en la posibilidad de cambio social. ${ }^{7}$ Si el cambio fue visto como algo inminente y natural, como sinónimo de eterno e infinito crecimiento y perfeccionamiento de la condición humana, el esplendor del espíritu humano fue alcanzado en los siglos XVIII y XIX con la modernidad europea por contraposición a la antigüedad grecolatina, que fue seguida de una sucesión ordenada, inexorable, gradual, continua, lineal y acumulativa a lo largo del tiempo hasta desplegar ilimitadamente — según se creyó en esos siglos_ - las alas de la plenitud moral, social y del conocimiento.

Es de llamar la atención que el México decimonónico no estuvo al margen de esta oleada ideológica que se expandió desde Europa hasta los confines más diferenciados y remotos que recibieron al progreso como una idea esquiva, distorsionada/distorsionante, deforme, y distante en el horizonte futuro.

JOSÉ MARÍA LUIS MORA Y LUCAS ALEMÁN: DEL OPTIMISMO A LA BÚSQUEDA DEL PROGRESO EN MEDIO DE LA DESARTICULACIÓN DEL MERCADO

Pese a no materializarse las banderas sociales inspiradas por los intelectuales y líderes del movimiento insurgente, se logró la independencia política y legal de México. Al no atacarse los problemas sociales prevalecientes en la colonia y al continuar intactos los privilegios de las clases dominantes, en un contexto marcado por la quiebra económica 
de la nación y en especial del erario público, se pretende enfrentar el desafío de organizar los destinos del naciente país independiente. ${ }^{8}$ En esos primeros pasos posteriores a 1821 , se transita del entusiasmo a la desesperación y el desastre. ${ }^{9}$ Los primeros treinta años de vida independiente, aunque se pensó en un modelo de país en el que prevaleciese la paz, el orden y el bienestar social, se caracterizaron por graves conflictos y guerras intestinas. Las luchas por influir en las estructuras gubernamentales y en el rumbo de las reformas sociales fueron las principales contradicciones que se presentaron entre los grupos privilegiados. Por si fuera poco, algunos autores hablan de que entre 1820 y 1840 se experimentó un periodo de depresión económica y desintegración del mercado interno. ${ }^{10}$

Mientras que la revolución industrial inglesa y el comercio internacional se expandían por Europa desde finales del siglo XVIII a través del fuerte estímulo brindado por los gobiernos, la economía mexicana padecía condiciones desastrosas y adversas: a) persistía una escasez de capitales derivada del drenaje de recursos emprendido por la metrópoli, así como de la destrucción causada por las guerras internas, en tanto que el capital existente se canalizó —en detrimento de la producción- a la especulación y a la usura controladas por la jerarquía católica que mantenía su poder económico; b) un comercio internacional prácticamente deprimido, en tanto que las pocas importaciones desplazaron — por su calidad o precio- a los productos nacionales, de tal forma que al restringirse aquellas se estimuló el contrabando; c) un mercado interno frenado por la destrucción de la infraestructura y la creciente inseguridad pública; d) la corrupción gubernamental y los excesivos impuestos sobre el comercio interno (alcabalas); e) una agricultura dependiente principalmente de frutos para la satisfacción de las necesidades de las pequeñas comunidades, puesto que las haciendas padecían la baja productividad; y f) la quiebra y descapitalización de las minas. Sin embargo, del último cuarto de siglo de la sociedad colonial, son rescatables las reformas

8 Sobre este punto, véase Humboldt 2002.

9 Brom 1998.

${ }^{10}$ Cárdenas 2003. 
borbónicas que inspiraron —a través de su ideología liberal—incipientes aires industrializadores en la economía novohispana, al tiempo que se levantaron parte de las prohibiciones comerciales y el cultivo de gran cantidad de productos agropecuarios.

En medio de esta generalizada desorganización, las pocas y desarticuladas acciones estatales en materia económica — tomando en cuenta que gran parte del escaso gasto público fue absorbido por el gigantesco ejército-, se centraron en impulsar la creación de fábricas mediante créditos, en fomentar y atraer la inversión extranjera, y en otorgar facilidades para la importación de materias primas. Aunque algunos sectores de la economía se estabilizaron y reorganizaron, el crecimiento fue lento y contradictorio; ya no se diga el bienestar social que brillaba por su ausencia en medio de los insuficientes y deficientes servicios sanitarios y educativos. Además, como las débiles finanzas públicas y la insuficiencia de ingresos no procuraron los recursos necesarios para satisfacer la administración pública y la seguridad interna, ni contribuyeron al estímulo de la economía y la defensa de la soberanía nacional, se abonó para que se contratasen deudas con otros países, regularmente en condiciones desventajosas para México.

Se trataba de un México predominantemente agrario (agricultura de autoconsumo y para el mercado interno) y preindustrial, con importante peso de actividades extractivas y de exportación como la minería; asumida esta como fuente crucial de la riqueza y favorecida por importantes reducciones fiscales y demás estímulos gubernamentales. Pese a la incipiente expansión de algunas ramas industriales, durante las primeras décadas del siglo XIX primó — en este escenario de confrontación bélica y política - un limitado proceso de acumulación de capital, la destrucción de la actividad productiva y la irradiación de la especulación comercial. De ahí que, por una parte, quienes se aferraron a la actividad productiva, reivindicaron ideas propias del centralismo, el proteccionismo y el conservadurismo para impulsar — a partir de la industrialización textil gestada endógenamente- la autonomía en un eventual proyecto de nación; en tanto que quienes propugnaron por los intereses del capital comercial privilegiaron el liberalismo, el federalismo, el librecambismo 
y la sujeción a la división internacional del trabajo como pilares de la modernización económica del país al privilegiar la remoción de las prohibiciones y la especialización en la generación de materias primas para satisfacer la demanda externa. Ambos proyectos divergentes bien fueron legitimados por sus exponentes a través del mantra ilusorio del progreso. De esta forma, en medio del optimismo suscitado con el logro de la independencia política respecto a España, México padecía la desorganización económica y del espacio público. La sociedad — predominantemente rural y agrícola - aún estaba sitiada por privilegios corporativos heredados de la época colonial. A la par de la recepción que se hace en el país del liberalismo europeo, la idea de progreso influye en aquellos pensadores mexicanos que esbozaron estrategias para la organización del proceso económico. Entre 1821 y 1853, fue clara la oposición entre quienes proclamaron el laissez-faire, laissez-passer — y, por tanto, el «libre comercio»- y aquellos que recurrían a la intervención directa o indirecta del sector público en la economía —o sea, al proteccionismo de la industria- Dos fueron las concepciones sobre el progreso económico en esa época: 1) el progreso como secularización a través de la supresión de los privilegios corporativos (militares y eclesiásticos) en condiciones de un proceso económico espontáneo y natural guiado por las aspiraciones y acciones de un individuo libre; y 2) el progreso como modernización del aparato productivo con base en el «espíritu de empresa» y el fomento gubernamental.

A grandes rasgos, las principales necesidades a partir de 1821 radicaron en la pretensión de revertir la desorganización de la vida pública, impulsar la formación de un Estado moderno, y procurar la integración nacional en medio del caos, la inestabilidad política, la persistente estratificación social y de los intereses creados heredados de la colonia y perpetuados a través de los arreglos concertados —en un escenario de violenciaentre los propietarios de la tierra y de las minas, los comerciantes, las autoridades clericales, y los mandos militares que ejercían el pillaje de minerales y controlaban el mercado interno y las vías de comunicación para el comercio de mercaderías. A su vez, este escenario convulso — radicalizado con las invasiones extranjeras, la carestía, la generalizada 
inseguridad pública, el hambre, el bandidaje, el contrabando y otros flagelos - propició la creación de un pensamiento que sentó las bases de las más importantes reformas del siglo XIX mexicano.

Uno de los personajes que esbozó con mayor claridad un pensamiento económico medianamente estructurado fue José María Luis Mora (1794-1850). Los planteamientos de este intelectual se inspiraron en la economía política clásica — especialmente en su vertiente utilitarista-, así como en el supuesto de que el monopolio representaba el principal obstáculo para la existencia y despliegue de un sistema económico gestado de manera espontánea. Sus ideas adquirieron fuerza en el marco de la secularización y de la lucha contra las corporaciones eclesiásticas proclamadas por la Reforma Liberal de 1833-1834. Particularmente, en el Programa de los principios políticos redactado por el doctor Mora como plataforma del Partido del Progreso - y que rigió el gobierno encabezado, durante algunos meses, por Valentín Gómez Farías (1781-1858)—, condensa parte de la concepción sobre el progreso en preceptos como la libertad de opinión; la abolición de privilegios clericales y militares (en tanto obstáculos al cambio social); la supresión de las instituciones monásticas que incidían en la vida civil; la necesidad de reconocer, clasificar y solventar el servicio de la deuda pública; facilitar la circulación de la propiedad territorial e incrementar el número de propietarios, especialmente entre las clases indigentes; la mejora de las condiciones de vida de las clases populares a través de la ruptura del monopolio clerical sobre la educación pública; la abolición de la pena capital para los delitos políticos; y la integración del territorio nacional a través de la colonización y la reafirmación de una cultura mexicana. ${ }^{11}$ De tal modo que en su revisión y análisis de la historia de México, el progreso es concebido, en lo fundamental, como reforma. ${ }^{12}$

En la base de la concepción de progreso esbozada por Mora, se encuentra la idea de que la libertad, en un sistema económico natural, supone la supresión de los monopolios y —en general— del espíritu

\footnotetext{
${ }^{11}$ Mora 1837: CXI y CCLXXII; Mora 1994a.

${ }^{12}$ Esta idea sobre el curso de la historia se observa en Mora 1965.
} 
corporativo y de las prohibiciones que pesaban sobre las empresas. ${ }^{13}$ No coincidía con las estrategias de fomento, pues asumía que estas, en sí mismas, implicarían obstáculos para el progreso en tanto el gobierno tendiera a intervenir y manipular la economía. ${ }^{14}$ Como la iglesia fue considerada por este pensador como el principal monopolio, sugería la necesidad de liberar los capitales amortizados e introducirlos al dinamismo del proceso económico, situándolos como base del crédito público. ${ }^{15}$ Incluso ideólogos y legisladores como Lorenzo de Zavala (1788-1836) apostaron a la nacionalización de los bienes de «manos muertas» y a su reparto entre los desposeídos.

Las reticencias expresadas por el doctor Mora en torno a las estrategias de fomento pretendidas con base en la utilización de las propiedades eclesiásticas desamortizadas se fundamentaron en la premisa liberal de que el proceso económico debe estar separado de la organización política de la sociedad, puesto que el poder del Estado tiende a distorsionarlo. Más bien, la supresión de los bienes de «manos muertas», en su concepción, serviría para forjar y fortalecer una clase de pequeños propietarios individuales y rurales dedicados a la agricultura; en este sentido, la tierra fue concebida por Mora como la fuente principal de la riqueza. En su modelo, se reconoce implícitamente que la acumulación de capital se realizaría de manera natural y espontánea una vez suprimidos los privilegios corporativos. Un Estado fuerte solo tenía cabida en la medida en que a partir de ello se debilitasen los poderes económicos e ideológicos del clero. Especialmente, el doctor Mora en su Marcha politica de progreso hizo énfasis - lejano de la influencia clerical, apegado desde 1824 al laicismo y opuesto a la influencia de las oligarquías - en la difusión y masificación de la educación pública, así como en la libertad de enseñanza y la planificación científica de la misma. Estos últimos fueron preceptos expresados en la Ley de Instrucción Pública promulgada en 1833,materializándose en medidas como el cierre de la Real y Pontificia Universidad

\footnotetext{
${ }^{13}$ Hale 1994: 266.

${ }^{14}$ Mora 1837; Hale 1994: 266-267.

${ }^{15}$ Mora 1994b: 13-157.
} 
de México por «inútil, perniciosa e irreformable»; la oposición a la formación monacal que privilegió la devoción, el encierro y el castigo entre los jóvenes, así como la difusión de conocimientos desfasados de la realidad; $y$, en general, en los cimientos de una reforma educativa que propugnó por ajustar la enseńanza al nuevo contexto histórico e incentivar a las masas para acercarse — a partir del cuestionamiento del dogmatismo - al aprendizaje y a la duda, así como situar a la educación en la base del bienestar social, entendido este como la mayor suma de bienes a disposición de los sectores populares.

Esta noción de progreso se cimentó en el ideal de un mundo rural y agrario que brindase los insumos y mercancías para estimular las exportaciones agrícolas y mineras (los metales preciosos financiarían el comercio internacional); al tiempo que la industrialización fue desdeñada al considerar que sería ruinosa para los inversionistas. De ahí que la libertad fuese un valor central en esta concepción y se entendiese como el interés individual regido por la libre competencia; ello en oposición a los privilegios y monopolios corporativos — sean militares o clericales - dotados de poderes simbólicos, ideológicos, políticos y económicos heredados de la sociedad colonial y que se caracterizaron por condicionar los mecanismos espontáneos orientados al progreso y a la distribución «natural» de la riqueza. En consonancia con todo ello, el mismo doctor Mora y otros ideólogos como Manuel Ortiz de la Torre

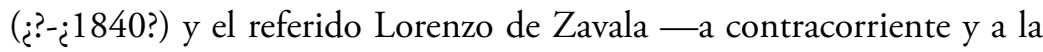
vez en concordancia acrítica con Adam Smith (1723-1790) — fundamentaron la riqueza de la nación en una ciudadanía sustentada en la pequeña propiedad agraria y el trabajo libre y, a su vez, contrarios a las prohibiciones arancelarias, al fomento industrial y a la intervención del Estado en el proceso económico, pues en su sociedad ideal la producción sería regulada por el «libre juego» de la demanda interna y externa, que — por sí misma - garantizaría la libertad de intercambio. Por tales razones, para estos ideólogos mexicanos, si el proceso económico es regulado por obra y gracia de los mecanismos de la oferta y la demanda, el Estado sería reducido a un guardián y árbitro que orientaría sus funciones a la procuración de la armonía social. Es de destacar que en ideólogos 
como Zavala y Ortiz de la Torre se expresa cierto desdén por el pasado mexicano y una admiración desmedida hacia el modelo económico y político de la naciente sociedad estadounidense, al extremo de desear seguir los senderos trazados por esta nación. ${ }^{16}$

En general, estos pensadores que introdujeron el liberalismo en México mostraron más una actitud pragmática y orientaron sus idearios no a desentrañar las contradicciones estructurales de la economía mexicana, sino a legitimar las actividades de los comerciantes y agiotistas que — vinculados a los mercados internacionales - controlaban el sector financiero y porciones importantes de los ingresos de la hacienda pública, provenientes de las aduanas fronterizas y marítimas. Los transportes, las vías de comunicación, los puertos y demás infraestructuras orientados al intercambio eran controlados por estos agentes económicos concretos que, más allá de ideologías aperturistas o proteccionistas, se preocuparon por incrementar el peso específico de su poder. Con sus cuantiosos recursos, los comerciantes financiaron las arcas del Estado y al resto del empresariado privado, pues se erigieron en especuladores y agiotistas de la deuda pública y en acreedores de terratenientes, mineros y pequeños industriales. Esta estrechez de miras se explica por la obsesión en la creencia de la espontaneidad del mercado y el llamado librecambio.

Estos primeros ideólogos liberales (que al estar activos en la vida pública, cristalizaron algunos de sus preceptos en el movimiento de reforma de 1833-1834) fundamentaron su concepción del progreso en mínimas bases para la construcción de un Estado mexicano modernizado, apegado al laicismo y desatado de las cadenas clericales y económicas heredadas de la Colonia. Los entramados jurídicos de la época y de décadas posteriores se inspiraron en ello, y sirvieron de sustento para las reformas educativas y hacendarias que perfilaron un nuevo escenario institucional en el país.

Propiamente en la función de estadista, Gómez Farías mostró una postura de liberalismo radical y, en consonancia con los pensadores referidos, observó en la Iglesia y la milicia el principal freno del progreso 
nacional; y a partir de la llamada Primera Reforma, orientó sus esfuerzos a socavar la estructura jurídica que — desde la Colonia - entronizó a la Iglesia en las jurisdicciones propias de la vida civil. En sus concepciones, la educación es la fuerza motriz del progreso y la libertad; de ahí la importancia de masificar y secularizar la enseńanza. ${ }^{17}$

Como expresión de una perspectiva liberal más arraigada en el proteccionismo, y con una orientación más pragmática —influida por sus intereses empresariales, primero en la minería y luego en la industria textil — Lucas Alamán (1792-1853) en un principio orienta sus reflexiones a rescatar y regenerar — mediante la introducción de modernas técnicas - la actividad minera, pues, a partir de ella, la agricultura y la industria serían impulsadas.${ }^{18}$ Para la promoción de la minería, Alamán consideró importante la atracción de inversiones extranjeras, pues, la misma inversión del gobierno le parecía insuficiente; al tiempo que sugirió el impulso a la industria manufacturera a través de la protección arancelaria. Sin embargo, es hasta 1830 —en un contexto signado por una crisis económica nacional derivada de los limitados flujos de inversiones extranjeras, la carencia de capital interno y las resistencias del clero para realizar inversiones productivas - cuando se marcan las diferencias respecto a la concepción del doctor Mora y trasciende, en este escenario adverso, la simple protección de los intereses y técnicas de los grupos artesanales locales.

Como ministro del Interior y de Relaciones Exteriores e inspirado en las tesis de Henri de Saint-Simon (1760-1825), Alamán propuso el fomento gubernamental para la modernización de la industria. ${ }^{19}$ Entre las medidas recomendadas, destacaron: a) limitar la industria fabril a la producción de telas baratas; b) la apertura del Banco de Avío para canalizar inversiones a la industria en un inicio; c) la supresión de las prohibiciones que se impusieron a las telas de algodón durante el gobierno

${ }^{17}$ Para mayores detalles sobre su pensamiento, véase Hutchinson, 1983; Santos Valdés, 2002; Fuentes Díaz, 1991.

${ }^{18}$ Hale 1994. Sobre el pensamiento de Lucas Alamán, véase Gonzáles Navarro, 1952 y 1953.

${ }^{19}$ González Navarro 1952: 84. 
de Vicente Guerrero (1782-1831); y d) la importación de maquinaria. ${ }^{20}$ En estas propuestas de Alamán, se observa una intervención directa del gobierno en el proceso económico. Para 1844, el estadista guanajuatense amplió su concepción sobre el progreso, pretendiendo armonizar los alcances de la industria con la agricultura y procurando el resurgimiento de las políticas borbónicas de fomento —estímulo gubernamental en campos escogidos, exenciones de impuestos, manipulación de los aranceles, importación de maquinaria y tecnología - con la finalidad de promover la regeneración nacional a partir de un espíritu industrial sin que ello implicase forjar una sociedad industrial urbana bajo criterios modernos. ${ }^{21}$ No menos importante fue, para Alamán, el problema de la inseguridad pública y las cuantiosas guerras intestinas que, aún hacia 1840, asolaban la naciente nación.

En última instancia, lo que Alamán pretendía con sus tesis fue reducir las asimetrías internacionales a partir de la creación de mínimas condiciones internas. Para ello, en un primer momento, el guanajuatense sugirió convencer a los mineros y terratenientes para que canalizaran sus inversiones a la industria textil y a la adopción de nuevos métodos tecnológicos; sin embargo, esta pretensión se enfrentó a la profunda descapitalización de la economía mexicana. A la par de lo anterior, Alamán pensó también en que la inversión extranjera directa y el gasto público — sufragado este por los aranceles — fuesen dirigidos al financiamiento de la iniciativa privada para que sus miembros se convirtiesen en industriales productores de bienes de consumo baratos asequibles para las clases populares; ello sin descuidar actividades económicas tradicionales como las agropecuarias y la minería en aras de no depender del exterior. Particularmente, la regeneración de las actividades económicas extractivas suponía la atracción de capitales extranjeros y la disminución de impuestos a la producción y exportación de minerales. De ahí que en estas tesis proteccionistas subyace la idea de que tanto el Estado como los entramados jurídicos estarían en función del fomento, la regulación

\footnotetext{
${ }^{20}$ Alamán 1830; Hale 1994: 275-276.

${ }^{21}$ Alamán 1977; Hale 1994: 287.
} 
del proceso económico y de la intervención pública en el mismo. Sin embargo, el coqueteo de Alamán con el intervencionismo estatal fue más por conveniencia ante la generalizada crisis económica nacional, el desinterés del alto clero a invertir en la producción y la falta de inversión de capitales nacionales y extranjeros. Estas adversidades condujeron a Alamán a promover, en 1830, la fundación del Banco de Avío; idea original del funcionario del Ministerio de Hacienda Ildefonso Maniau y Torquemada Sanchiz (1768-i?) y atacada por los librecambistas en sus primeros años de operación, incluido el mismo doctor Mora (1836 y 1837), quien sugería impulsar a los terratenientes y no fomentar una industrialización forzada. ${ }^{22}$ Este instrumento tuvo como finalidad adoptar estrategias de fomento de las actividades industriales a partir del financiamiento público, cobrando un $5 \%$ de intereses en proyectos productivos considerados viables a los ojos de sus directivos. ${ }^{23}$ Desde años anteriores, los intereses corporativos de los grupos de artesanos se opusieron a las estrategias de estímulo de la demanda entre los estratos medios que ejercen actividades fabriles y mercantiles, así como al financiamiento para la creación de fábricas por parte de terratenientes, comerciantes y mineros. Estas estrategias de fomento, finalmente, se impusieron desde el Estado y se extendieron hasta muy entrada la década de los cuarenta, con importantes beneficios para los nuevos grupos industriales en detrimento de los artesanos que se enfrentaron sin protección a las manufacturas nacionales y a las provenientes del exterior. Uno de los primeros antecedentes proteccionistas con tintes sociales fue el expuesto por el federalista Manuel Crescencio Rejón (1799-1849) al argumentar - respecto a la necesidad de reivindicar los derechos e intereses de los consumidores en situación de pobreza- una estrategia aperturista que no tomaría en cuenta la oferta de prendas extranjeras de algodón a precios accesibles, además de propugnar por la abolición de la opresión que recaía sobre las comunidades autóctonas. ${ }^{24}$ Sea en el ámbito legislativo o entre

${ }^{22}$ Mora 1965: 513.

23 Sobre la fundación y objetivos del banco, véase Potash 1953 y 1986.

${ }^{24}$ Rejón 1943: 249. 
los gobernadores, durante la década de los años veinte del siglo XIX, fueron extendidas también las posturas liberales en pro de los intereses propios de los productores y artesanos locales gestados desde la Colonia. Una muestra de ello fue la disposición emitida por Vicente Guerrero en 1829 para prohibir la importación de materias primas como el algodón y proteger así la producción artesanal.

A grandes rasgos, Alamán no pretendió romper el cordón umbilical que lo ataba a las instituciones y herencias coloniales, sino modernizar esos lazos e incorporar a los empresarios industriales como nueva élite económica; lo que es lo mismo a considerar —inspirado, en parte, en Edmund Burke (1729-1797), su tendencia al individualismo y en su hostilidad hacia la Revolución francesa, pero sobre todo en las ideas económicas y borbónicas que guiaron a la corona española- una colonia con industria que perpetuara los intereses clericales al oponerse a la circulación de las reservas de capital en manos de la iglesia vía la desamortización de las tierras proclamada, de manera prioritaria, por los reformistas liberales de 1833-1834. ${ }^{25}$

Otro personaje pragmático como Estevan de Antuñano (1792-1847) - fundador de la primera fábrica algodonera en el país, llamada La Constancia Mexicana - sugirió que la grandeza nacional se lograría mediante la industria; de ahí que resultase necesario revitalizar, modernizar y defender la fabricación de tejidos. ${ }^{26} \mathrm{Su}$ interés sobre el progreso radicó en preocupaciones patrióticas, pues reconoció que si en México solo se impulsaba la agricultura y la minería, se corría el riego de la dependencia económica respecto a los países industrializados. En sus aspiraciones —y desde una óptica propia del individualismo económico— resultaba necesario crear un espíritu de empresa entre la población. En general, sostuvo que el progreso del país basado en la industria sería factible con la adopción de una decidida política de fomento estatal que contemplase entre sus postulados la concesión de privilegios a las clases productivas, y la no reducción de los aranceles para impulsar a las industrias nacientes. ${ }^{27}$

\footnotetext{
${ }^{25}$ Esta idea puede rastrearse en Reyes Heroles 1974: 168-169.

${ }^{26}$ Antuñano 1837 y 1845b; Hale 1994: 281.

27 Hale 1994: 283.
} 
Inspirado también en Saint-Simon, el referido empresario de origen poblano redactó folletos propagandísticos en los que abordó problemas productivos concretos, y lo hizo dotado de vastos referentes empíricos, así como de polémicas en torno a los pros y contras del proteccionismo; adelantándose incluso al Sistema Nacional de Economía Política publicado en 1841 por Friedrich List (1789-1846). ${ }^{28}$ Respecto a las manufacturas de algodón, Antuñano vio con buenos ojos las estrategias de fomento estatal, así como las prohibiciones y aranceles sobre las manufacturas extranjeras, particularmente sobre la abundancia de productos textiles ingleses. Además, reconoció como problema la limitada producción nacional de algodón; de ahí que propusiese la importación gravada de este insumo y se prohibiese la compra de tejidos. A su vez, la pobreza de las mayorías se encontró también entre sus preocupaciones y, ante ello, no escatimó en sugerir la creación de empleos para mujeres e infantes en los establecimientos fabriles; $y$, en general, la promoción de empleos productivos e industriosos para combatir la pobreza y - ante el caosrestablecer el espíritu público y el orden político y legal. ${ }^{29}$ En última instancia, su concepción de progreso — ante lo que se consideró como un colonialismo económico- atravesaba por la necesidad de procurar la independencia industrial de México a partir de su modernización tecnológica, la adopción de estrategias prohibicionistas respecto a las importaciones textiles y de algodón y del espíritu de industria o de empresa que estimula valores cívicos; aunque también teniendo como referente a la economía y sociedad estadounidenses. ${ }^{30}$ Es de destacar que esta concepción no cuestionó el poder económico del clero — pero vio con buenos ojos la libertad de culto, la restricción del poder político/ ideológico de la iglesia y la desamortización de los bienes clericales para fundar y financiar bancos de avío en las entidades federativas-, ni abogó por el fraccionamiento de la propiedad laica acaparada en pocas manos. ${ }^{31}$

\footnotetext{
${ }^{28}$ Sobre el argumento de Saint-Simon, véase Reyes Heroles 1994: 469.

${ }^{29}$ Antuñano 1834, 1838a y 1893.

${ }^{30}$ Antuńano 1845a:b, 1837, 1838a. 1839 y 1846.

${ }^{31}$ Antuñano 1834 y 1846.
} 
Hacia 1837, Antuñano le otorgó prioridad a la necesidad de coordinar el Estado y el mercado para fomentar el proceso de industrialización; al tiempo que partió de la crítica al carácter atrasado de la metrópoli española y las técnicas y maquinaria que llegaron a la Nueva España desde esas latitudes europeas. ${ }^{32}$ De ahí que en su proyecto de progreso, de lo que definió como «la grandeza de la patria industrial», fuese relevante - en aras de contener la dependencia tecnológica respecto a las naciones industrializadas - el aprovechamiento de recursos minerales como el hierro para la fabricación nacional de máquinas y herramientas que sirviesen en el campo y en la industria. ${ }^{33}$ Sin embargo, estas propuestas de política se enfrentaron a un contexto adverso signado por las crisis económicas, la carencia de materias primas como el carbón, el contrabando y la especulación con el precio del algodón —lo cual derivó en su aumento-, el proteccionismo comercial de las naciones industrializadas, la incapacidad del Estado mexicano para materializar las estrategias prohibicionistas e industrializadoras, e, incluso, al divisionismo y a la falta de consenso político en torno a la necesidad de fomentar una industria nacional. Más aún, como lo observa Carlos Marichal, el financiamiento público canalizado desde el Banco de Avío terminó en manos de agiotistas y especuladores que, con ello, incrementaron sus fortunas en un proceso de acumulación privada de capital a expensas del erario público. ${ }^{34}$

Es de llamar la atención que el Banco de Avío -clausurado en 1842 por decreto del general Antonio López de Santa Anna (1795-1876) — fue cuestionado radicalmente por los ideólogos del libre mercado, succionado por aquellos deudores que no realizaban sus pagos y ahogado por la carencia de recursos públicos que dependían de los impuestos y aranceles comerciales. ${ }^{35}$ A este banco de fomento le sucedió, promovida por el mismo Lucas Alamán, la Dirección General de la Industria Nacional con la finalidad de adoptar una estrategia de política económica para otorgar créditos a la industria, eximir de impuestos al sector, aplicar medidas

\footnotetext{
${ }^{32}$ Antuñano 1837 y 1838 b.

${ }^{33}$ Antuñano 1837: 17.

${ }^{34}$ Marichal 1992.

${ }^{35}$ Véase Potash 1953 y 1986.
} 
comerciales proteccionistas respecto a los tejidos e hilados provenientes del exterior, y agilizar — desde el gobierno central — la fase de circulación de mercancías por el territorio nacional. Estas medidas no dieron los frutos deseados, pues se generalizó la quiebra de empresas textiles a raíz del encarecimiento del algodón y otras materias primas, la situación de insolvencia de los empresarios para liquidar sus deudas, y la abundancia de inventarios en los almacenes y bodegas.

A grandes rasgos, entre 1821 y 1853 , la construcción de un proyecto de nación sólido y consistente fue pospuesta y, en ocasiones, se diluía ante las divisiones de la heterogénea clase política: por un lado, los llamados conservadores aspiraban a lograr la estabilidad política a través de un régimen centralizado, con un gobierno firme encabezado por un monarca o por un presidente poderoso; por otro, los llamados liberales - que pretendieron un gobierno sujeto a la voluntad de los ciudadanos - le apostaban a una república federal que dotara a las entidades federativas de amplios poderes. La confrontación de ambas tendencias ideológicas derivó en múltiples revueltas locales y en el fortalecimiento de los cacicazgos regionales, profundizando con ello la desorganización del Estado. Los diversos golpes militares en las sucesiones de los gobernantes, la inestabilidad política interna, los conflictos internacionales y las intervenciones extranjeras, el descontento popular y la debilidad de las instituciones influyeron también en esta desorganización de la vida pública y en las posibilidades de desmembramiento del país; lo cual, finalmente, se evitó a pesar de que en 1848 se perdió más de la mitad del territorio nacional en el contexto del expansionismo estadounidense del este al oeste.

En cuanto al proceso económico, los problemas estructurales se agravaron hacia 1850 y luego de que las políticas proteccionistas y prohibicionistas no cristalizaron en una pujante industrialización, el poder monopólico se cernió sobre la vida comercial y el mercado financiero al extremo de extender sus tentáculos hacia aquellas empresas fabriles que fueron vendidas por su situación de insolvencia y que se otorgaron en prenda por los préstamos concedidos. No menos importante fue el grillete que pesó sobre la posible articulación del mercado interno 
ante las limitaciones que impuso el hecho de no contar con una vasta red de comunicaciones y transportes que permitiese movilizar — con eficiencia - capitales y fuerza de trabajo. La carencia de capital suficiente y adecuado, así como de mano de obra calificada y medios de producción modernizados fueron otros handicaps que limitaron el proceso de industrialización. Lo anterior, pese a que se produjo el suficiente pańo para vestir y satisfacer las necesidades de las clases populares.

Hacia aquellos ańos que rebasaban la mitad de la centuria, la madurez que alcanzaron las tesis ricardianas y el resto de la economía política clásica revitalizó la discusión entre ideólogos aperturistas e industrializadores a la luz no solo del ideario para conformar un proyecto nacional de progreso; sino de los intereses concretos del empresariado que ya sobresalía, en la conformación de una industria mexicana, que eran preciso defender con esas ideas. Salvo el diputado y estadista tapatío Mariano Otero Mestas (1817-1850), que reivindicó el ideario de los liberales mexicanos de los años treinta, el resto del debate público mantenía reservas respecto a las polémicas de lustros anteriores y se guió más por las necesidades y cambios concretos de la economía nacional. En su calidad de ministro de Hacienda, Manuel Payno (1810-1894) realizó esfuerzos para poner fin a las estrategias proteccionistas de la industria; $y$, ante ello, el incipiente empresariado industrial no se mantuvo indiferente, sino que reaccionó con determinación para defender sus intereses y culpar al librecambismo del desastre generado en la economía mexicana en aras de favorecer a las naciones industrializadas. Sin embargo, hacia 1857, se impusieron las voces liberales en el contexto de un renovado debate político del Congreso Constituyente y de las Leyes de Reforma, que derivó en el fortalecimiento del Estado mexicano en detrimento del incipiente proyecto industrial fomentado en las décadas anteriores.

\section{EL LIBERALISMO SOCIAL, LA TRANSFORMACIÓN ESTRUCTURAL DE LA ECONOMÍA Y LA GESTACIÓN DE LA IDENTIDAD DEL ESTADO MEXICANO}

Los primeros visos de ruptura definitiva con las estructuras y prácticas socioeconómicas coloniales se presentaron con el movimiento de Reforma. El desafío a enfrentar fue representado por la grave y 
generalizada crisis del país, que afectó a amplios sectores populares hundidos en la miseria, mientras que el clero, los hacendados y los especuladores incrementaban sus fortunas. Aún entre 1850 y 1870 , persistió la desintegración del mercado interno, pero de manera gradual se despertó del letargo y se tendió a una lenta recuperación económica. ${ }^{36}$

En el plano de las ideas, el camino adoptado por el liberalismo mexicano desde 1821 adquiere un rumbo distinto al no concretarse el librecambio y al fortalecerse el proteccionismo. Además, como consecuencia de la miseria y de la manifestación de los movimientos sociales de la época, persistió la necesidad de transformar la propiedad territorial. Esto último, en sí mismo, le otorgó un carácter eminentemente social al liberalismo mexicano. ${ }^{37}$

En la multitud de debates suscitados entre 1854 y 1876, se esbozó una concepción del progreso que asumió como central la resolución de los problemas relacionados con la desigual distribución de la tierra y con la marginación y autogobierno de las comunidades autóctonas. El origen de los males sociales, la miseria y de la esterilidad de la tierra se atribuyó a la concentración de la propiedad territorial. Entre los movimientos sociales que reclaman esto y que se desenvuelven después de la guerra contra los Estados Unidos, destacan los siguientes: el comunismo agrario, que declaró a la tierra como propiedad común a todos los mexicanos; la guerra social yucateca —o de castas—, que proclamó la secularización, el igualitarismo, la reivindicación del indígena, y la supresión de cargas religiosas y civiles; y el ejército regenerador de Sierra Gorda — que emitió el plan político de Río Verde (San Luis Potosí)—; el cual hizo referencia a la secularización de la sociedad y a la necesidad de crear una ley agraria. ${ }^{38}$

En el Congreso Constituyente de 1856-1857, se gestó una concepción social del derecho de propiedad como resultado de la convergencia de los principios del individualismo y el socialismo, y de la gravitación de movimientos sociales como los anteriores. El artículo 17 del proyecto

\footnotetext{
${ }^{36}$ Cárdenas Sánchez 2003: capítulo IV.

${ }^{37}$ Reyes Heroles 1994.

${ }^{38}$ Reyes Heroles 1994: 568-576; Brom 1998.
} 
de Constitución Política propuso la desamortización de los bienes tanto eclesiásticos como laicos, así como la definición del derecho de propiedad a partir de la libertad de trabajo.

Ponciano Arriaga (1811-1865) —uno de los prominentes diputados constitucionalistas - se pronunció por cambiar la organización social de la propiedad imponiéndole límites, definiendo a esta como una función social y como un hecho político que se confirma con el trabajo y la producción. ${ }^{39} \mathrm{El}$ abogado y legislador potosino — aunque limitando, más no atacando, a la propiedad privada — se manifiesta contra el latifundio, su ociosidad y la pobreza de las mayorías. Anteponiendo una perspectiva federalista, en su concepción del progreso se muestra defensor del valor de la ley, de la laicidad del Estado y de la educación popular y gratuita; así como de la libertad de culto y la absoluta separación Estado-iglesia. Inspirado en los debates revolucionarios franceses de 1848 , en el epicentro de su pensamiento social, se ubicó la población rural excluida, asediada por la desigualdad y desposeída de hogar, empleo y propiedad territorial.

Francisco Díaz Barriga, con relación a los problemas del campo, consideró que la concentración de la propiedad y los monopolios son injustos; además, propuso reducir la oferta de mano de obra para aumentar su precio. ${ }^{40}$ Se trata de un liberalismo económico radical basado en la idea de la circulación y división de la propiedad territorial y en la necesidad de dejar a la economía expuesta al libre juego de sus fuerzas, pero reconociendo que la causa del atraso del país y la armonía social no serían dejadas en manos de la espontaneidad de las fuerzas del mercado, pues las leyes desempeñarían la función de proteger a la sociedad ante la desigualdad.

Por su parte, José María Iglesias (1823-1891) asume que el derecho de propiedad es la base más firme de la subsistencia de las sociedades; también, a pesar de mostrar una postura antiindigenista y de oponerse a la división de la tierra por considerarla un derecho natural, sugiere una legislación protectora de los jornaleros, considerando que la solución

\footnotetext{
${ }^{39}$ Arriaga 2011b; Reyes Heroles 1994: 592-597.

${ }^{40}$ Reyes Heroles 1994: 609.
} 
de sus problemas no atraviesa por la vía agraria, sino por la organización del trabajo. ${ }^{41}$ Dotado de un importante sentido y filosofía de la historia influidos por el positivismo, rechazó toda tiranía y dictadura que amenazase la libertad individual, al tiempo que desplegó sus ideas como funcionario y ministro de Hacienda, Justicia y de la Suprema Corte, y como promotor de la Ley del 25 de junio de 1856, relativa a la desamortización de corporaciones civiles y eclesiásticas - propuesta por Miguel Lerdo de Tejada (1812-1861), entonces ministro de Hacienda-, y de la Ley de Abolición de las Obvenciones Parroquiales del 11 de abril de 1857 , que eximía a los pobres de cualquier gasto religioso. ${ }^{42}$

Además de los problemas agrarios de México, los liberales atendieron otros relacionados con los trabajadores de los sectores industrial, minero y comercial. En especial, se pone atención en la miseria del proletariado y a la concentración de la riqueza; en concreto, se proponía que los trabajadores tuviesen participación en los beneficios de las empresas. Por su parte, Ponciano Arriaga habló de la necesidad de crear procuradurías de pobres para la protección y defensa — desde el Estado- de los grupos sociales marginados, vulnerables y desvalidos ante los excesos del poder público. Con la figura del procurador de pobres, se aspiró a promover el bienestar mediante la asistencia social, la enseñanza, educación y moralidad del pueblo. ${ }^{43}$

Por su parte, Ignacio Ramírez «El Nigromante»(1818-1879), al preocuparse por los asalariados y los indígenas, postula la redistribución de la riqueza y de la propiedad, así como la instrucción popular mediante una educación dirigida a finalidades prácticas y al bienestar de la población. Además, al considerar que la apropiación del trabajo ajeno acumulado es el origen de la riqueza y al oponerse al maquinismo, critica la persistente explotación y servidumbre capitalista de los jornaleros y propone el establecimiento de un salario de subsistencia y la participación de los trabajadores en las ganancias o utilidades. Recomienda que los trabajadores, al asociarse en colectivo, dominen la oferta de trabajo.

\footnotetext{
${ }^{41}$ Reyes Heroles 1994: 613; Iglesias 1893.

${ }^{42}$ Véase Iglesias 2003.

${ }^{43}$ Arriaga 2011a; Reyes Heroles 1994: 648-650.
} 
También argumenta en contra de la usura y el capital improductivo y a favor de la reglamentación de la propiedad. Su vocación antiestatista y antiproteccionista lo conduce a afirmar que el Estado contribuye a la opresión de los pobres, por lo que se pronuncia a favor de las asociaciones civiles voluntarias de profesionistas que apuesten al reconocimiento de los derechos del obrero y a la autoorganización espontánea de la sociedad, encarnando valores como la comunicación, libertad, igualdad, fraternidad, voluntad y democracia. ${ }^{44}$ Por tanto, considera que intervenir y moderar la sociedad desde el poder y administración del Estado es una tiranía que atenta contra la naturaleza, la espontaneidad y la libertad. Más aún, con su característica sátira política, señaló que el Estado es un instrumento de manipulación para la defensa de la riqueza y la preservación de los privilegios a partir de la irradiación de la desigualdad; de ahí que repudiase toda institución (el comercio, la farmacia, el matrimonio, el poder ejecutivo, etc.) por ejercer su dictadura sobre la voluntad, libertad y autonomía de los individuos. ${ }^{45}$ Ante todo ello y en su concepción sobre el progreso, para este diputado constituyente resultó capital el acceso popular a la educación, las bibliotecas y el conocimiento científico en aras de satisfacer las necesidades sociales y el ejercicio de los derechos individuales, en tanto el sustento de toda institución de la sociedad. De ahí que para "El Nigromante», el progreso impulsado por la ley —entendiendo a esta no como una estructura estática, sino como aquello que se corresponde con las transformaciones de la realidadconsiste en conciliar el orden con el movimiento y en sujetar el poder político y jurídico a las necesidades populares, de tal modo que sea una beneficencia organizada.

En todo momento, se mantuvo firme en la creencia referida a las capacidades del pueblo para con la luchas políticas y en su voluntad como fuente del poder público; depositando dicha fe en la soberanía del municipio y sus ayuntamientos. A partir de esto último y abrevando del pensamiento de John Locke (1632-1704), abogó por un sistema

${ }^{44}$ Ramírez 1889a, 1889b, 1889c; Reyes Heroles 1994: 655-674.

${ }^{45}$ Ramírez 1889d: 380. 
político parlamentario y por la supremacía del poder legislativo a partir de un régimen representativo que se nutra del razonamiento y deliberación colectivas, y no de sufragios dispersos y atomizados; de tal suerte que en su concepción de progreso subyace una radical defensa de la democracia tras conciliar nociones como soberanía popular, división de poderes, control legal del poder público y garantías individuales que, en conjunto, confeccionan el contrato social. ${ }^{46}$ Para aspirar a todo ello, resultaba fundamental la reivindicación de la opinión pública y la libre manifestación de ideas, así como la libertad de imprenta en el sistema político representativo.

Inspirado en el naturalismo y el radicalismo social, Ramírez fue un crítico mordaz de la sociedad cambiante de su tiempo. Además, motivado por las herencias intelectuales de Jeremy Bentham (1748-1832), Adam Smith (1723-1790) y el movimiento filosófico de la Ilustración europea, se pronunció a favor de la república, el federalismo y la educación del indígena, y en contra de los absolutos y dogmas teológicos y metafísicos, así como de la opresión de las mayorías y los privilegios de la Iglesia católica, definiendo a esta como el principal enemigo del progreso. Su pensamiento político se dotó también de una propensión al individualismo (la felicidad del hombre como fin último de las instituciones sociales) y centró a las garantías individuales y el respeto a la vida humana como fundamentos supremos de la democracia. Bajo estas premisas, consideró que la sociedad y su inalienable derecho a protegerse es un individualismo aritmético dado por la igualdad y el derecho contractual a la asociación. ${ }^{47}$ Es de destacar que, si bien se inspiró en el pensamiento ilustrado europeo, no toleró la imitación mecánica de modelos y prácticas provenientes de otras latitudes, pues promovió el hispanoamericanismo y asumió a México como una nación diferente en la que urgía reconocer la diversidad de idiomas y razas para darle forma a la Constitución Política de 1857 y al nuevo Estado-nación. ${ }^{48}$

\footnotetext{
${ }^{46}$ Ramírez 1889a, 1889 b.

47 Torres 1962: 217.

${ }^{48}$ Ramírez 1889a. Para profundizar en este prolífico pensador, consúltese Torres 1962 e Ibarra García 2012.
} 
En general, múltiples debates de los liberales de este periodo se sintetizaron en la Ley de Desamortización de Bienes Eclesiásticos del 25 de junio de 1856, en la Ley de Nacionalización y en el artículo 27 de la Constitución Política de 1857. Sin embargo, al final de este sendero legislativo, no se abordó la transformación de la estructura de clases sociales ni la desconcentración de la propiedad laica. Aunque, en general, es de destacar que, en el papel, las estrategias proteccionistas fueron suprimidas de la citada Carta Magna y las tesis económicas liberales gozaron de gracia durante el periodo transcurrido entre 1867 y 1876, conocido como la República Restaurada.

La secularización de la sociedad y la circulación de la riqueza a través del libre movimiento de la propiedad se expresaron de manera más clara con la radicalización del pensamiento liberal y en la expedición de las llamadas Leyes de Reforma entre julio de 1859 y diciembre de 1860. Las Leyes de Reforma consistieron en un conjunto de preceptos y disposiciones orientadas a la construcción nacionalista de un Estado moderno de orientación liberal y con una identidad definida consistentemente, al margen de la influencia eclesiástica. Se institucionaliza la separación entre el Estado y la Iglesia, y en síntesis se decreta en ellas: 1) la nacionalización de los bienes de la Iglesia; 2) el establecimiento del registro civil, concediéndole al matrimonio la naturaleza de contrato civil; 3) la secularización de los cementerios, quedando estos bajo la inspección de la autoridad estatal; 4) el decreto de los días festivos y la prohibición de la asistencia oficial a las funciones y festividades eclesiásticas; y 5) la libertad de cultos como derecho natural del individuo.

Con las Leyes de Reforma, por primera vez en la vida independiente, se apuesta seriamente a la formación de instituciones estatales y a la consolidación de las ya existentes. Además, le fue cancelado el derecho de voto al clero, se suprimieron los fueros de este, se le sustrajo el control de la educación y lo sujetaron a las leyes generales que regían la vida de toda la población. Por si fuera poco, se emprendió la secularización de los hospitales y demás establecimientos de beneficencia, así como la desamortización de las propiedades de corporaciones civiles o eclesiásticas para que sus dueños las vendiesen a sus arrendatarios; con lo cual se pretendía 
impulsar la propiedad privada y el crecimiento de la economía, pero sobre todo reducir el poder económico y político del clero. Sin embargo, la ley que canceló la propiedad comunal indígena terminó por promover el latifundismo en detrimento de estas comunidades y a favor del despojo de sus propiedades. El aumento de las haciendas acentuó la miseria en el campo y no permitió la plena industrialización del país, por lo que los grandes beneficiados fueron los capitales extranjeros. Particularmente, la Ley Lerdo tomó en cuenta la venta de los bienes de "manos muertas», pero otorgó al clero una serie de réditos tras la nacionalización, y abrió el camino para la formación de latifundios laicos debido a que las clases populares no podían adquirir las fincas desamortizadas; y al aplicarse dicha legislación a las comunidades indígenas, se propició el despojo, el parcelamiento y la disolución del ejido.

De nueva cuenta y a raíz de la Constitución Política de 1857 y de las Leyes de Reforma, la crisis política y social estalló en el país; situación que se agravó con la crisis de las finanzas públicas y la onerosa carga de la deuda externa. Después del gobierno presidido por Ignacio Comonfort (1812-1863), se sucedieron en la administración pública varios líderes del partido conservador, en tanto que Benito Juárez (1806-1872) ejercía paralelamente el poder de manera itinerante en plena Guerra de Reforma (1858-1861). Las pugnas entre los gobiernos liberal y conservador se extendieron por todo el país con apoyos extranjeros para ambos, pero al final —en enero de 1861 - triunfa el gobierno constitucional encabezado por Juárez y se restaura la paz y su autoridad nacional. La economía seguía estancada y se deterioraba aceleradamente; además, persistían la miseria y la explotación del pueblo.

Al poco tiempo, de los desafíos internos, como parte del reacomodo de las clases políticas dirigentes, se transitó al problema internacional gestado con la intervención francesa que tuvo como aliados a los conservadores derrotados. Estos acontecimientos fueron facilitados por la economía deprimida que dejó la Guerra de Reforma y por la carencia de recursos en el erario público debido a la erogación de egresos destinados al ejército y al pago de la deuda externa. La nación se volvió a cimbrar con la guerra, a tal grado que el gobierno juarista reanudó su paso itinerante 
por el territorio nacional, y los conservadores y liberales moderados constituyen un gobierno imperial (1864) con la firme intención de anular las Leyes de Reforma, lograr la paz y consolidar la independencia. Sin embargo, el emperador Maximiliano de Habsburgo (1832-1867) ratificó la vigencia de estas medidas y emprendió un gobierno que se caracterizó por el despilfarro de las finanzas públicas. Posteriormente, las mismas contradicciones internacionales entre las potencias hegemónicas propiciaron ciertas condiciones para el triunfo y la restauración de la República.

Estos acontecimientos consolidaron y reorganizaron a México como Estado-nación con caracteres republicanos. A pesar de que múltiples prácticas y estructuras coloniales desaparecían y se afirmaba la soberanía nacional, se acentúo la discriminación, la distribución desigual de la riqueza y las condiciones de pobreza entre las mayorías. Los gobiernos siguientes procuraron mantener la soberanía y aplicar las Leyes de Reforma; las cuales fueron incorporadas en 1873 a la Constitución Política por el gobierno de Sebastián Lerdo de Tejada (1823-1889).

Los presupuestos públicos fueron favorecidos con la reorganización y reducción del ejército, medida que se acompañó del equilibrio entre ingresos y egresos del gobierno y con la reducción de la deuda pública. Con el afán de fomentar la integración nacional y procurar el crecimiento industrial y comercial, el gobierno amplió las comunicaciones mediante la instalación del telégrafo y la red de caminos, y se inauguró el ferrocarril de la capital del país a Veracruz. Se impulsó la economía de mercado, teniendo como base a la hacienda y el respeto de la propiedad privada individual. Particularmente, la desamortización de los bienes eclesiásticos redundó en la circulación de capital orientado a la producción; significando ello una importante transformación de la estructura económica mexicana al iniciarse una especie de acumulación originaria del capital.

La gran diferencia — a pesar de que postularon los mismos principios ideológicos - entre el liberalismo mexicano encarnado por Benito Juárez y el liberalismo de Maximiliano radicó en lo opuesto de sus proyectos institucionales: uno proclamaba la República y la construcción de un proyecto nacional anticolonialista y basado en el control de la iglesia; 
y el otro, el régimen imperial y la modernización de México para que trascendiese hacia el rango o estadio de las sociedades europeas. ${ }^{49}$ Las similitudes entre ambos liberalismos y concepciones de progreso radicaron en otorgar derechos civiles a la población, así como la laicidad de la educación y la libertad de pensamiento y de culto.

Es precisamente el triunfo del liberalismo encabezado por Juárez -y ratificado por Maximiliano - el cimiento sobre el cual se erigirá el naciente Estado-nación mexicano que por fin impuso su soberanía respecto a la Iglesia católica. Al final de cuentas, en sus concepciones sobre el progreso, tanto liberales como conservadores coincidían en el respeto a la propiedad privada; sus diferencias, fundamentalmente, radicaron en lo relativo a la desamortización y nacionalización de los bienes del clero propuesta por los primeros. El progreso, pues, se concebía como un resultado de la formación del Estado-nación — tras la supresión de los fueros-, de la procuración de la estabilidad sociopolítica, y de la libertad en el proceso económico. Además, estuvo presente la necesidad de generar una conciencia o un sentimiento nacional identitario.

En materia estrictamente económica, Guillermo Prieto (1818-1897) se preocupó desde los tiempos de la dictadura santanista por la crisis fiscal del Estado y la generalizada crisis económica; y, ante ello, adoptó una tercera vía respecto al librecambio y el proteccionismo, reconociendo los derechos de productores y consumidores, y las posibilidades de fraude y contrabando ante la aplicación de los aranceles; por lo que sugiere una institucionalidad adicional a la estrategia arancelaria. ${ }^{50}$ Aunque a lo largo de su vida pública fluctúa entre una posición y otra, hasta rozar el antiproteccionismo tras considerar a las prohibiciones como lesivas debido a que se protege la producción nacional y se solapa la oferta de bienes caros y de mala calidad. ${ }^{51}$ Por si fuera poco, de cara a la asfixia prohibicionista santanista, el comercio internacional fue visto por algunos pensadores como Miguel Lerdo de Tejada como la salida a la crisis económica y,

\footnotetext{
${ }^{49}$ De Borbón 2004.

${ }^{50}$ Prieto 1850 y 1906.

51 Prieto 1871 y 1888 .
} 
desde una óptica antiproteccionista, pretende amalgamar el progreso económico y la realidad política. ${ }^{52}$ De ahí que el fomento y el crecimiento industrial se sujeta a la competencia internacional, combinado ello con gravámenes arancelarios moderados aplicados a las mercaderías extranjeras con la finalidad de evitar la quiebra de los empresarios nacionales y, a su vez, continúen — dichos aranceles — sufragando los ingresos fiscales del Estado y el fomento de la industrialización. ${ }^{53}$

En general, la idea de progreso expresada por los pensadores de estos años, tuvo sus orígenes en la educación ilustrada que recibieron. ${ }^{54}$ Algunos — como Francisco Zarco (1829-1869), audaz defensor de la libertad de expresión - asumieron al progreso como un camino inmanente a la humanidad, y si bien pueden presentarse episodios de regresión a un estadio ya superado, al final, lo nuevo triunfa sobre lo antiguo y la costumbre cambia, se modifica y se perfecciona en un sentido progresivo, siendo pues el triunfo de la democracia el destino de la humanidad. ${ }^{55}$ Otros como Ignacio Manuel Altamirano (1834-1893) concibieron al progreso fundado en el respeto a la libertad en tanto fuerza motora de la sociedad; y en ello desempeñaban un relevante papel las artes y la música para gestar asociación, consuelo y esperanza. ${ }^{56}$ Para otros más —que eran la mayoría - el concepto de progreso se relacionó con Dios, pues asumían que el mundo marchaba hacia la perfección dirigido por un ser supremo. ${ }^{57}$ Así, a juzgar por la misma Pi-Suñer Llorens, la historia fue concebida como una larga y ardua marcha evolutiva hacia el triunfo del progreso y de la modernidad, concibiendo a cada fase como superior a la anterior. ${ }^{58}$

${ }^{52}$ Lerdo de Tejada 1853.

$53 \mathrm{Ib}$.

${ }^{54}$ Pi-Suñer Llorens 1996: 21.

55 Pi-Suñer Llorens 1996; Zarco 1857; Castañeda Batres 1961; Woldenberg 1996.

56 Pi-Suñer Llorens 1996; Altamirano 2013.

${ }^{57}$ Pi-Suñer Llorens 1996.

${ }^{58}$ Ib.: 22. 


\section{LA CONCEPCIÓN POSITIVISTA DEL PROGRESO Y LA CENTRALIDAD DEL ESTADO PORFIRISTA EN LA ECONOMÍA NACIONAL}

A pesar de la restauración de la República, los liberales y conservadores seguían en confrontación y, además, persistían las sublevaciones militares e indígenas a lo largo y ancho del país. Entre 1867 y 1876, aparecieron indicios de cierta consolidación de la nación y de sus estructuras e instituciones políticas; sin embargo, predominó también el enfrentamiento entre los caudillos militares y civiles, y entre la institución presidencial y la legislativa debido a la premura de la primera por conformar un gobierno central y fuerte en sus funciones. A la par de esta inestabilidad política, la gran deuda legislativa del movimiento de Reforma consistió en que los liberales no crearon la estructura jurídica propia del proceso económico, necesaria para la profundización y el definitivo arraigo del capitalismo.

Esta creciente tensión fue contenida con el ascenso del gobierno liderado por el General Porfirio Díaz (1830-1911), quien a lo largo de más de tres décadas centralizó el poder político y transformó la economía nacional con el impulso a la industrialización incipiente y la integración del mercado interno a través de los ferrocarriles. Paralelamente, cabe enfatizar, en este periodo se agravaron las contradicciones sociales.

Entre 1876 y 1888 , al no dominar totalmente en lo político, el gobierno de Porfirio Díaz impulsó la consolidación de su poder mediante la represión, la concesión de privilegios a sus adversarios y el debilitamiento de los poderes locales y regionales que anteriormente no reconocían a la autoridad federal. A pesar de que continuó la vigencia de las Leyes de Reforma, el poder político y económico del clero adquirió relevancia. En suma, se pretendió generar condiciones internas propicias para lograr el reconocimiento internacional y — con ello- atraer corrientes de inversión extranjera, principalmente canalizadas a la construcción de ferrocarriles que partían desde los Estados Unidos hacia el centro de México. Esto último afianzó la dependencia económica respecto al país del norte, a pesar de que se adoptaron medidas simultáneas para contrarrestarla al estimular la atracción de capitales europeos.

Las actividades mineras crecieron y se modernizó la agricultura para reorientarla hacia la exportación, principalmente de henequén y café 
en detrimento del maíz y el frijol. Se ampliaron considerablemente las vías férreas para la integración terrestre de ciertos espacios del mercado interno y comenzó a acuñarse moneda con reconocimiento oficial. Con todo ello, se fortaleció el gobierno federal y se ampliaron los privilegios de los hacendados y terratenientes. En general, los esfuerzos del sector público se canalizaron al impulso de la industria nacional, la atracción de inversiones y al desenvolvimiento del comercio. Estos avances económicos, conjuntamente con la promesa de procurar el orden y la paz, brindaron legitimidad y fortaleza al entonces grupo gobernante. Solo los dirigentes militares y «Los Científicos» se disputaban la hegemonía al interior de la administración pública. Los segundos asumieron a la ciencia como la única vía para impulsar el progreso nacional; en tanto que sus miembros se aliaron con inversionistas extranjeros, sirviéndoles como gestores de concesiones realizadas por el gobierno. Este grupo gobernante, que impulsó la consolidación de una burguesía nacional favorecida por sus actividades empresariales y su influencia en el gobierno, se inspiró en la ideología del positivismo para esbozar su concepción sobre el progreso.

La doctrina positivista, de origen europeo, fue adoptada en el pasado inmediato por los liberales mexicanos mediante la introducción que hace Gabino Barreda (1818-1881) al fundar la Escuela Nacional Preparatoria en 1868, con miras a dotar de formación académica a la nueva clase intelectual que gobernaría el país con el objetivo de lograr progresos mediante el despliegue de la libertad dentro de los márgenes del statu quo, y de desplazar el control que la iglesia católica ejercía sobre la educación superior. En su Oración cívica, interpreta a la historia mexicana como una sucesión de etapas que alzan su vuelo hasta alcanzar la emancipación mental tras desvanecer el poder clerical y desterrar la ignorancia, la convulsión social y la inestabilidad política; de ahí que el liberalismo y las Leyes de Reforma fuesen, para Barreda, la cúspide del espíritu positivo, y la educación — liberadora más no adoctrinadora - el camino para alejar el estado teológico e instaurar un nuevo orden social sin anarquía. ${ }^{59}$ 
Augusto Comte y Herbert Spencer fueron dos de los pensadores europeos que mayor influencia ejercieron en México hacia la segunda mitad del siglo XIX. Para estos filósofos, el progreso era la máxima ley social, expresando con ello un optimismo por las posibilidades de avance o evolución, e incluso de regeneración de la especie humana. ${ }^{60}$ Solo que en el caso de Spencer, el progreso de la evolución social resultó ser más naturalista que en el caso de Comte, puesto que este recurría a la ciencia como actividad organizadora y racionalizadora de la sociedad. Para el pensador francés, el progreso consistió en la forma de pensar (teológica, metafísica y positiva) de los hombres, sea en el plano individual o colectivo; mientras que para Spencer, el progreso era el avance de la capacidad de adaptación de los hombres a los cambios inevitables en sus circunstancias. ${ }^{61}$

Leopoldo Zea explica que el positivismo, en tanto ideología de las clases dominantes, fungió como una doctrina para imponer el orden que frenase la anarquía y la guerra civil; además de organizar el ejercicio de la libertad. Se trató de una doctrina que procuró el orden para guiar la libertad y el progreso. Fue importada y adoptada para servir como justificación a las acciones de un determinado grupo político y para consolidar la hegemonía de la naciente burguesía respecto a otras clases sociales. Se temían las transformaciones radicales, y como expresión ideológica del porfiriato y de "Los Científicos», justificó sus prerrogativas sociales y políticas al argumentar que el progreso genera una clase afortunada que — por poseer mejores aptitudes — representa la selección de las especies, detentando el derecho de explotar y someter a su dominio a los ineptos, y subordinando siempre el progreso al orden. ${ }^{62} \mathrm{Al}$ estado positivo, propio de las tres etapas señaladas por Comte, se le identificó con el porfiriato en tanto este régimen emprendía la reconstrucción y reorganización del país; creyendo tener a la libertad como medio, al orden como base y al progreso como fin mientras se defendía la propiedad privada y su

\footnotetext{
${ }^{60}$ Hale 1991: 337; Comte 1980; Spencer 1851.

${ }^{61}$ Hale 1991: 347.

${ }^{62}$ Zea 1968.
} 
concentración en unas cuantas manos. ${ }^{63}$ Por si fuera poco, se adoptó el precepto comteano de que la acción del Estado en la vida social sería guiada por el conocimiento científico tras desentrañarse las leyes del comportamiento de las sociedades y el devenir histórico. ${ }^{64}$

Una suerte de «darwinismo social spenceriano» — compaginado con un racismo legitimado mediante cierto talante científico- que asumió a la selección natural como la supervivencia del más apto en el marco de una concepción lineal, progresiva y teleológica de una historia con sociedades estratificadas en razas que pilotean dicha evolución y otras que marchan a la saga de la misma a causa de su condición primitiva y rezagada. ${ }^{65}$ Estas distorsionadas nociones darwinianas y lamarckianas de la evolución - matizadas con las tesis malthusianas de la competencia o lucha feroz y despiadada - engarzaron con la decimonónica idea de progreso arraigada en las sociedades occidentales, donde triunfó el movimiento filosófico de la Ilustración europea. De ahí que para Spencer, el Estado se ciñese a la procuración del orden y a garantizar la propiedad privada en el contexto del despliegue de leyes naturales que, espontáneamente y por su propia inercia, devendrían en el progreso de la sociedad. ${ }^{66}$ Esta evolución spenceriana — tras adoptar tesis transformistas que se oponen a las funciones que el británico le otorgó al Estado- se gesta a través de rasgos y conductas adquiridas por la vía de la educación y que se heredan de generación en generación en el marco de un proceso lineal y acumulativo.

Estas nociones, para el caso del mestizaje como condición del progreso y la evolución social, subyacen en la amplia obra histórica coordinada por Vicente Riva Palacio (1832-1896) y titulada México a través de los siglos. Allí se consigna el argumento de la superioridad evolutiva de la raza amerindia por sobre las razas africanas y europeas; al extremo de definir al progreso como un proceso que remite a la superioridad de las sociedades originarias de América por sobre otras razas, en tanto

\footnotetext{
${ }^{63}$ Divisas estas enunciadas por Barreda 1979: 19.

${ }^{64}$ Comte 1980.

${ }^{65}$ Spencer 1867 .

${ }^{66}$ Spencer s.f.
} 
acumulación de los rasgos y caracteres que son útiles e indispensables para que los organismos luchen y sobrevivan, y la consiguiente desaparición de aquellas características inútiles y dañinas que predominaron en organismos del pasado. ${ }^{67}$

En este ambiente intelectual de la época, los positivistas mexicanos encabezados por Gabino Barreda se oponían a la intervención del Estado en la reglamentación de la propiedad privada; reduciendo únicamente sus funciones a la formación moral de la población mediante la educación. ${ }^{68}$ Propugnaron, además, por la protección de la riqueza desde las instituciones estatales sin intervenir en la administración y decisiones que los particulares adoptasen sobre ella. Se trataba, desde su perspectiva, de «humanizar a los ricos» en el entendido de que el desorden de la sociedad tiene su origen en el desorden de la conciencia; por lo tanto, esta debía ser uniformada u homogeneizada a través de la educación para evitar la anarquía. ${ }^{69}$ En suma, al progreso se le concebía únicamente como el aumento acelerado, lineal y progresivo de la riqueza, justificado ello en nombre del bienestar social que solo se presentaría en la medida que fuese sometida la libertad individual. La lógica de este pensamiento asumió que la libertad resulta del progreso material de la civilización. Como la base de todo ello fue el orden guardado mediante la fuerza, la planificación educativa sería fundamental para contener la tiranía, la violencia y la anarquía derivadas de la ausencia de creencias seguras.

El mismo Leopoldo Zea explica que la teoría del orden social que fundamentó toda esa perspectiva justificó la posición que se tiene o que se desea alcanzar en la sociedad; esto es, todos los hombres tienen un puesto que determina las relaciones entre unos y otros: a unos les corresponde dirigir y a otros, obedecer. A partir de ello, se sugirió abnegación de los superiores para con los inferiores; respeto y veneración de los inferiores hacia los superiores. Este discurso sirvió para que en el porfiriato se asumiera que no existiese oposición alguna a un gobierno cuyos objetivos

${ }^{67}$ Riva Palacio 1888: 474-476.

${ }^{68}$ Para mayores detalles sobre el pensamiento de Barreda y su obra educativa, véase Zea 1963.

69 Zea 1968; Barreda 1979. 
consistían, se decía, en la realización de la paz y el progreso; de esa forma, lo único permitido sería la veneración, el respeto y la gratitud en el marco de un statu quo. ${ }^{70}$ Con esta inconsistente y engañosa concepción sobre el progreso y con las funciones que el gobierno desempeñó en la economía, se emprendió la defensa de los intereses de la burguesía; que fue considerada como una clase superior moral e intelectualmente al detentar la riqueza. Por tanto, el aparato de Estado debía estimular a los más aptos y proteger sus conquistas, reforzando el poder dictatorial, utilizando incluso a la ciencia social de la época en la solución de los problemas; o sea, fue preciso gobernar, legislar y orientar la política de conformidad con las leyes científicas descubiertas y demostradas. Además, se consideró que la industrialización sería un mecanismo del orden social al evitar la confrontación nacional y al hacer de la naturaleza un instrumento para la satisfacción del ser humano y para el logro del progreso.

A grandes rasgos, la concepción sobre el progreso que predominó durante amplios episodios del porfiriato consistió en postular un Estado fuerte y represor, garante de un orden político que fuese la base del progreso económico de cara a la persistente desorganización de la vida nacional y las guerras intestinas; las amenazas e intervenciones militares extranjeras; y la creciente competitividad que imponía la renovada división internacional del trabajo. Se consideró que de estos factores dependía la misma existencia y viabilidad de la nación mexicana.

Para un pensador y estadista como Justo Sierra Méndez (1848-1912), la igualdad de derechos en una sociedad solo se suscita a través del progreso alcanzado con el trabajo estimulado por un gobierno que se encargaría de garantizar el orden necesario para ello. Si bien fue escéptico del positivismo comteano, en su ideario político proponía reorganizar la administración pública, en especial al sector militar que absorbía gran parte de los recursos públicos; proporcionar al régimen tributario bases científicas; así como suprimir las aduanas interiores para hacer viable el comercio nacional. ${ }^{71}$ Aunque Sierra propugnó por un activo papel del

\footnotetext{
70 Zea 1968.

${ }^{71}$ Sierra 1977a.
} 
Estado en el proceso económico, sus intervenciones serían sometidas a meticuloso análisis a partir de las especificidades del momento histórico y de las necesidades de la sociedad; de ahí que en el caso de México se precisase — por su grado de progreso económico — de una mayor presencia estatal. Mostrando con esta tesis serias reservas respecto al supuesto virtuosismo de las fuerzas del mercado en la asignación de recursos (pues aún continuaban prisioneras del aislamiento territorial), la carencia de comunicaciones y transportes y las herencias coloniales, así como sitiadas por el trueque y una estructura económica de autoconsumo. ${ }^{72}$ En este tenor, Sierra consideró relevante la adopción de la ciencia del gobierno para la resolución de los problemas públicos. ${ }^{73}$

Sierra — al igual que Spencer — definió a la sociedad en términos biológicos y la entendía como un organismo dotado de un doble movimiento de integración y diferenciación, y regido por las leyes de la evolución, la selección natural, la lucha por la existencia y el progreso de lo homogéneo a lo heterogéneo; de ahí que este proceso — el progreso- consiste en un perfeccionamiento del organismo, pues a medida que se integra o vertebra en una unidad, tiende a diferenciarse o a especializarse. ${ }^{74}$ Pero a contracorriente del pensador inglés inclinado al individualismo, el mexicano apostó por el fortalecimiento de la regulación e intervención gubernamentales para contrarrestar la anarquía, procurar el progreso económico y alejar la amenaza de los Estados Unidos en tanto «organismo más poderoso». En ese sentido, y con miras a contar con un mecanismo de cohesión que procurase la integración de las partes del organismo en aras de su diferenciación, proponía un Poder Ejecutivo lo suficientemente fuerte para procurar el orden. Sin embargo, el educador campechano no se proclamó ni cercano al intervencionismo estatal a ultranza, ni siquiera convencido de las supuestas bondades del laissez faire et laissez passer y su mercado autorregulado; mucho menos miró con buenos ojos la expansión de las burocracias como fuente de empleo de la clase media

\footnotetext{
${ }^{72}$ Sierra 1940.

${ }^{73}$ Sierra 1977 c.

${ }^{74}$ Sierra 1977b: 238-239; Hale 1991: 356.
} 
ante la estrechez de la economía mexicana. ${ }^{75}$ En suma, se adhirió a una propuesta liberal de corte pragmático que buscó sintetizar el interés social con el derecho individual y en asumir al progreso como evolución del orden; en ello, la educación sería fundamental para la promoción e impulso de dicho progreso. ${ }^{76}$ A grandes rasgos, en su pensamiento se impone — fuertemente apegado al «darwinismo social spenceriano» y más allá de los liberalismos radicales de décadas previas - un conservadurismo liberal, en el cual el progreso se logra por la vía de la evolución y no de la revolución; teniendo al orden como fin último y como fundamento para el logro de la libertad y el progreso, en tanto que la educación —impulsada por un Estado fuerte capaz de gestar cohesión social— sería el medio esencial para combatir la anarquía y el caos de la vida nacional. «Los Científicos» aseguraban que el progreso se alcanzaría mediante el trabajo. ${ }^{77}$ Más aún, para obtener la libertad resultaba indispensable fortalecer el orden. El orden posibilita el progreso y este, a su vez, hace posible la libertad que tiende a mejorar la situación económica del individuo — en especial de la burguesía mexicana—, incluso en detrimento de la libertad y de los derechos políticos ${ }^{78}$. El pragmatismo de esta élite política - a diferencia de los principios abstractos y metafísicos defendidos por los liberales que intentaron las reformas de 1833-1834 y de 1856-1857 - se fincó en la idea de que el Estado sería un instrumento de transformación social dentro de ciertos cauces que no escaparan al control centralizado del poder.

Entre las medidas de política económica emprendidas para procurar el progreso económico, destacaron la reorganización y equilibrio de los presupuestos de ingresos y egresos, el cumplimiento de los compromisos contraídos en materia de deuda pública, y la reducción y moralización de los funcionarios de la Secretaría de Hacienda. ${ }^{79}$ Se emprendió la recuperación de las Casas de Moneda para que fuesen administradas

75 Sierra 1878/1879: 239-240; 1900/1902: 24.

76 Sierra $1889 / 1890$.

77 Zea 1943/1944: 398.

78 Ib.: 402-403.

${ }^{79}$ Limantour 1965. Consúltese también Díaz Dufoo 1910. 
por el gobierno federal; así como la reorganización de los bancos y la procuración de la plena circulación de bienes y servicios al interior de la República a través de la supresión definitiva de las alcabalas y de los derechos de portazgo que imponían cuantiosos gravámenes desde la colonia. Se trató de medidas orientadas a facilitar la producción y circulación de la riqueza nacional; $y$, a su vez, contribuyeron a la ya mencionada centralización del poder político, en detrimento de las atribuciones de las entidades federativas. ${ }^{80}$

José Yves Limantour (1854-1935) —entonces ministro de Hacienda-, más que pronunciarse abiertamente por el mito de la libertad de comercio — aunque en su etapa pública inicial lo asumió—, considera, apegado a cierto eclecticismo, que la iniciativa individual debe ser estimulada por el gobierno mediante medidas proteccionistas provisionales. ${ }^{81} \mathrm{Se}$ procuró también la estabilidad de la moneda para brindar certidumbre a las transacciones comerciales con el exterior. Ya logrado el equilibrio fiscal en 1895 - mediante la disciplina en el gasto público, la mejora de la capacidad recaudadora y la reducción de impuestos- y con la contratación — cada vez más en condiciones favorables — de la deuda pública, se otorgó financiamiento a la construcción de ferrocarriles y a otras obras públicas. Otro asunto importante, y en torno al cual se esbozaron ideas que reforzaron la concepción sobre el progreso, fue el ingreso de México al patrón oro a principios del siglo XX ante el largo ciclo de depreciación de la plata en el mercado internacional. ${ }^{82}$

En esta concepción positivista del progreso económico, Limantour tuvo como telón de fondo la noción de que los supuestos y principios de la teoría económica pura solo se realizarían en un estadio superior de la evolución lineal de México. Recuérdese que para esos años ya estaba construido el edificio de la teoría económica neoclásica y la obra de Alfred Marshall (1842-1924) gozaba de amplia difusión e influencia en la vida académica y política.

\footnotetext{
${ }^{80}$ Ib.: 54-56.

${ }^{81}$ Ib.: 54-55. Consúltese también Díaz Dufoo 1910.

${ }^{82}$ Ludlow 2005; Romero 2005.
} 
Así, la supuesta tranquilidad que se vivió — puesto que las revueltas y los movimientos populares se presentaron con frecuencia y fueron fuertemente reprimidos_ y el apogeo aparente de 1900 a 1910 que — se proclamó- experimentaban tanto el país como el gobierno porfirista se argumentaron a través del prestigio internacional otorgado a México; las fuertes inyecciones de capital extranjero en la economía; los equilibrios presupuestales al administrar eficientemente los recursos y al cumplir con el servicio de la deuda; la construcción de imponentes obras públicas; y la relativa expansión de la enseñanza y las artes. ${ }^{83} \mathrm{~A}$ pesar de que el poder económico y político se concentró en pequeños grupos, el sector agropecuario se insertó aceleradamente al mercado interno y externo; las comunicaciones y transportes integraron el territorio y la economía nacional; al tiempo que el proceso de industrialización crecía, y el país — en su conjunto- se vinculó en mayor medida, con beneficios e inconvenientes, a la economía internacional.

Durante el régimen porfirista, los administradores públicos pretendieron impulsar una industria moderna y eficiente orientada al mercado internacional y financiada — principalmente-con inversión extranjera y una política de concesiones para la alta capitalización externa ${ }^{84} \mathrm{La}$ construcción de ferrocarriles fungió como detonador tanto de la industria como del comercio internacional, al tiempo que integraron parte del territorio nacional e impulsaron la minería mediante la disminución de los precios del transporte y el mejoramiento de estos servicios. Se inició la explotación de los recursos petroleros; aumentó la producción de artículos de consumo; la agricultura intensificó su producción debido a la fuerte demanda de los centros industriales y del mercado internacional, pero sin lograr satisfacer la demanda popular de maíz, trigo y frijol, y manteniéndose en un marcado rezago ${ }^{85}$ En general, el gobierno canalizó gran parte de sus acciones en el terreno económico a afianzar los privilegios del empresariado extranjero —que invertía ampliamente

\footnotetext{
${ }^{83}$ Brom 1998.

${ }^{84}$ Fenómeno definido como monopolio y seńalado ampliamente en Cabrera 1992.

${ }^{85}$ Brom 1998; Molina 1909.
} 
en minas, petróleo, industria y comercio- , aun a costa y en perjuicio de las masas populares.

Durante este periodo, fundamentalmente, se consolidó el largo proceso de formación del Estado. Ello permitió desarrollar aparatos e instituciones administrativos, legales y coercitivos mediante los cuales - y bajo los principios de la unidad y la centralización políticas - se articularon las relaciones entre las clases, los grupos y los centros de poder; además, se constituyó un espacio económico nacional que sirvió como base para la construcción de mercados de trabajo, de bienes y de capitales en el marco del proceso de modernización de la economía. ${ }^{86}$ Esto último fue impulsado por el aparato de Estado mediante su función de facilitador de la inyección de inversiones extranjeras y de la inserción en los mercados internacionales.

El crecimiento económico — caracterizado por ser desigual tanto entre regiones como entre sectores - dependió en lo fundamental de la dinámica de la economía internacional; especialmente del grado de difusión de la actividad exportadora sobre la totalidad del mercado interno, así como del resultado, monto y destino de la inversión extranjera. Sin embargo, este crecimiento económico — de 1900 a 1910 fue del 3.3\%—, que modificó lentamente la estructura productiva, fomentó los incipientes procesos de industrialización y urbanización.

Las funciones del centralizado Estado oligárquico del porfiriato, que resultaron esenciales en la consolidación de la economía, fueron múltiples: desde el fomento de los sectores exportador, extractivo (minería y petróleo) y agropecuario; el impulso a la inversión extranjera para su establecimiento y a las cordiales relaciones internacionales; hasta el resguardo de una relativa estabilidad social y política mediante la represión y el control sobre la vida pública. Todo ello guiado, en lo fundamental, por los principios liberales de la Constitución Política de 1857 y por el pensamiento positivista. Aunque fue importante la acción del Estado en la dinámica de la economía, sus limitaciones fueron impuestas mediante las funciones burocrático/administrativas y de procuración del orden social. 
Pese a estas acciones interventoras en el proceso económico, hacia el ocaso del Porfiriato se defendió - a contrapelo de los denominados colectivistas y estatistas - una postura liberal del progreso que vio en el colectivismo la disolución y sepultura definitiva de las fuerzas vivas de la sociedad, y en el estatismo el debilitamiento y estancamiento de las mismas; de ahí que la condición indispensable del progreso, de su incansable marcha y del bienestar de los desposeídos fuese la defensa del statu quo y el orden marcado por la propiedad y la iniciativa y libertad individuales. ${ }^{87}$

Sin embargo, las contradicciones sociales no se hicieron esperar: la clase media vio frustradas las posibilidades de mejorar su posición en la sociedad; predominaba la servidumbre y el latifundio en el campo, mientras que los obreros en las ciudades padecían la miseria y las condiciones laborales adversas. A decir de los estudiosos de la época, una de las tendencias que mostró el régimen político y económico a inicios del siglo XX y que no reconocieron sus élites, consistió — por un lado- en la mayor instrucción adquirida por las clases populares y obreras, $\mathrm{y}$ - por otro- el creciente poder monopólico del capital a partir de la incidencia del progreso tecnológico y de la combinación del individualismo con la competencia irrestricta. ${ }^{88} \mathrm{El}$ diagnóstico fue completado a través de la crítica al carácter concentrador del mercado mexicano piloteado por los monopolios extranjeros beneficiados con las políticas proteccionistas y las inercias del tardío proceso de industrialización; así como por la incapacidad y desinterés de las élites políticas para desamortizar los bienes en manos de los latifundistas de las regiones productoras de cereales, trastocando con ello el estatus concentrador de la propiedad territorial. ${ }^{89}$ No menos importante fue la identificación — desde dentro de la misma élite de «Los Científicos»— del problema relacionado con la propiedad territorial y que radicó en las resistencias a aplicar los métodos y conocimientos científicos y técnicos a la mejora de la producción agrícola y al aprovechamiento de los recursos naturales. ${ }^{90}$

\footnotetext{
${ }^{87}$ López Portillo y Rojas 1910: 248.

${ }^{88}$ García Granados 1906, 1909.

${ }^{89}$ Cabrera 1992; Molina 1909.

${ }^{90}$ Bulnes 1927.
} 
Dichas contradicciones sociales, que se agudizaron a pesar de la consolidación del Estado, se acompañaron de limitaciones generadas por este y que no facilitaron su flexible reacción ante la nueva naturaleza del proceso de desarrollo, lo cual derivó en una creciente inestabilidad tanto económica como política. Las variadas contradicciones y el acentuado descontento popular coincidieron — tal como en 1810 - con la inconformidad de grupos políticos y económicos poderosos del país que vieron limitados sus privilegios ante el fortalecimiento del poder de «Los Científicos", los grandes hacendados y de los inversionistas extranjeros. El motivo último que derivó en la agresiva ruptura del aparente orden social consistió en las disputas manifestadas durante la sucesión en el poder político; lo cual también facilitó la convergencia de empresarios nacionales, grupos de la clase media ilustrada, dirigentes locales y regionales, y de los obreros y campesinos marginados.

\section{CONSIDERACIONES FINALES SOBRE LA INVESTIGACIÓN}

Las breves pinceladas trazadas en las páginas anteriores evidencian la transformación y la complejización de las concepciones sobre el progreso, en tanto idea que despertó revuelo y expectativas en las diferentes generaciones de pensadores y políticos mexicanos a lo largo del siglo XIX y la primera década del siglo XX. Dichas concepciones — que limitamos a las estrategias económicas y al papel que se le asignó al Estado en el proceso económico - no fueron homogéneas, sino que se forjaron a las luz de las circunstancias históricas - tanto nacionales como internacionales-, de los intereses y decisiones de los principales actores partícipes en su formulación, y de la gravitación que ejercieron los debates intelectuales referentes a la filosofía política y a la teoría económica entonces en boga. Estos debates no siempre fueron asimilados de manera crítica, sino múltiples veces como una transcripción prácticamente mecánica, nostálgica y literal de los postulados europeos; ello acorde al momento histórico y a los intereses facciosos o de grupo que, en última instancia, pesaban sobre las concepciones de los intelectuales, legisladores y funcionarios públicos mexicanos. Por no mencionar que categorías usadas frecuentemente durante ese siglo — pensemos en liberales, conservadores, moderados, 
liberales conservadores, federalistas y centralistas-, remiten a grupos políticos o espectros ideológicos que sostienen más coincidencias y afinidades que diferencias marcadas, y no porque en sus argumentos y preceptos jamás subyació una transformación profunda de la estructura socioeconómica mexicana.

De ahí se desprende la necesidad de hablar de un pensamiento económico mexicano en tanto conjunto de ideas estructuradas orgánicamente para cumplir con dos funciones fundamentales: una positiva, destinada a la comprensión e interpretación de la manera en que se organiza el proceso económico, las relaciones sociales que le subyacen y las decisiones que adoptan los actores socioeconómicos; y una normativa, orientada a esbozar teóricamente las estrategias necesarias para hacer frente a los problemas derivados de las relaciones de producción, privilegiando — por supuesto - caminos y opciones, así como perfiles del tipo de intervención desplegada por el Estado. El grado de organicidad de los planteamientos depende del oficio intelectual y de las ideologías poseídos por los exponentes de las concepciones sobre el progreso.

Las enseñanzas de los pensadores y estadistas del México decimonónico estriban en la reivindicación y defensa de una serie de principios de respeto a lo público, tan urgentes en el México convulso y desintegrado de hoy. Estos principios comprendieron la necesidad de arrinconar los intereses facciosos y de grupo a favor de la construcción de un proyecto de nación dotado de una secularización del Estado y de una coherente ideología nacionalista liberal, que hizo valer la soberanía de cara a las cruentas amenazas externas, posturas e idearios que brillan por su ausencia en el México contemporáneo.

Es de destacar que el pensamiento mexicano decimonónico no es homogéneo ni monolítico; no es una pomposa y rimbombante propuesta teórica rebosante de creatividad, originalidad y conceptos genuinos; pero tampoco es una vulgar réplica o transcripción literal de las ideas europeas entonces en boga. Es más bien un vasto y multifacético paisaje sincrético dotado de vida propia, en diálogo permanente y en constante tensión y contrastación respecto a la lacerante realidad social y sus problemáticas. Si bien cabe postular que varios de estos pensadores, ideólogos y 
estadistas (re)visitados dejan de lado la dimensión procesual y sistémica de la realidad social y de la vida económica, de tal suerte que no son analizados en sus estudios y reflexiones las relaciones de poder y los problemas estructurales de la economía; cosa que sí lograron varios de los teóricos europeos que intentaron replicar.

Comprender históricamente la noción de progreso y la dinámica de su cristalización en debates públicos, estrategias de política, y en ciertas funciones del Estado en la vida social a lo largo del extendido siglo XIX mexicano, contribuye a rastrear la transformación de las ideologías que inciden en la praxis política y en la ardua configuración de un proyecto de nación que comenzó a fraguarse desde 1821. Este esfuerzo continuó — con claroscuros y altibajos - a lo largo del siglo XX, no sin las eternas sombras del pensamiento hegemónico y etnocéntrico proveniente de otras latitudes del mundo.

\section{BIBLIOGRAFÍA}

Alamán, Lucas. 1830. Memoria de la Secretaría de Estado y del Despacho de Relaciones Interiores y Exteriores. México: Imprenta del Águila.

. 1977. «Memorias de la Dirección General de la Industria Nacional». En Labastida, Horacio (comp.). Documentos para el estudio de la industrialización en México: 1837-1845. México D.F.: Secretaría de Hacienda y Crédito Público (SHCP) y Nacional Financiera.

Altamirano, Ignacio Manuel. 2013. «Influencia moral de la música». En Altamirano, Ignacio Manuel. Textos escogidos. México D.F.: Consejo Nacional para la Cultura y las Artes (Conaculta), 7-18.

Antuñano, Estevan de. 1834. Discurso analítico de algunos puntos de moral y economía politica de Méjico con relación a su agricultura cereal o sea pensamiento para un plan para animar la industria. Puebla: Imprenta del Ciudadano José María Campos. . 1837. Pensamientos para la regeneración industrial de México. Puebla: Imprenta del Hospital de San Pedro.

. 1838a. Economía Politica en México. De las clases productoras: su influencia sobre la riqueza, población, ilustración y espiritu público. Puebla: Imprenta de San Pedro.

1838b. «Ideas vagas para un plan de hacienda pública». En Quintana, Miguel A. Esteban de Antuñano, fundador de la industria textil en Puebla. Tomo II. México D.F.: Boletín Bibliográfico de la SHCP, Talleres de Impresión de Estampillas y Valores, 58-65. 
1839. Economía Politica en México. Exposición respetuosa que el que suscribe dirige a las augustas Cámaras de la Nación. Puebla: Imprenta antigua en el Portal de las Flores.

- 1845a. Economía política en México. Insurrección para la independencia industrial fabril. Simi alegórico del pueblo mexicano. Puebla: Imprenta Antigua en el Portal de las Flores.

. 1845b. "iii Mexicano!!! El primer asunto de la patria: insurrección para la independencia industrial fabril de México». El Siglo XIX, 2 de diciembre: x.

. 1846. Insurrección industrial. Economía Politica en México. Documentos para la historia de la industria moderna. Puebla: Imprenta Antigua en el Portal de las Flores.

Arriaga, Ponciano. 2011a. "El Estado y las garantías sociales. Establecimiento de las procuradurías de pobres”. Intervención del legislador Ponciano Arriaga en el Congreso de San Luis Potosí». En Primitivo Herrera, José. El legislador Ponciano Arriaga, 1811-1863. México D.F.: Editorial Miguel Ángel Porrúa y Cámara de Diputados, 59-90.

. 2011b. "Voto particular sobre la propiedad de la tierra”. Intervención del legislador Ponciano Arriaga en el Congreso Constituyente, 23 de junio». En Primitivo Herrera, José. El legislador Ponciano Arriaga, 1811-1863. México D.F.: Editorial Miguel Ángel Porrúa y Cámara de Diputados, 99-148.

Ayala Espino, José. 2001. Estado y desarrollo. La formación de la economía mixta mexicana en el siglo XX. México D.F.: Facultad de Economía de la Universidad Nacional Autónoma de México (UNAM).

Barreda, Gabino. 1979. Oración cívica. México D.F.: Universidad Nacional Autónoma de México.

Bock, Kenneth. 1988. «2. Teorías del progreso, el desarrollo y la evolución» En Bottomore, Tom y Nisbet, Robert (comp.). Historia del análisis sociológico. Buenos Aires: Amorrortu Editores, 59-104.

Brom, Juan. 1998. Esbozo de historia de México. México D.F.: Editorial Grijalbo.

Bulnes, Francisco. 1927. Los grandes problemas de México. México D.F.: El Universal. Cabrera, Luis. 1992. «El partido científico que fue, que es, que será, para que sirve la ciencia», en: Obra politica de Luis Cabrera, volumen I, México, UNAM.

Cárdenas Sánchez, Enrique. 2003. Cuando se originó el atraso económico de México. La economía mexicana en el largo siglo XIX, 1780-1920. Madrid: Editorial Biblioteca Nueva y Fundación José Ortega y Gasset.

Castañeda Batres, Óscar. 1961. Francisco Zarco. México D.F.: Club de Periodistas de México.

Comte, Auguste. 1980. Discurso sobre el espíritu positivo. Madrid: Alianza Editorial.

De Borbón, María Teresa. 2004. «Encuentro de dos liberalismos: similitudes y diferencias». En Galeana, Patricia (coord.). Encuentro de liberalismos. México D.F.: Universidad Nacional Autónoma de México, 79-83. 
Díaz Dufoo, Carlos .1910. Limantour. México D.F.: Editorial Gómez de la Puente. Enríquez Pérez, Isaac. 2016. Las estrategias de desarrollo y los avatares de la planeación nacional: un estudio sociohistórico para la reconstrucción de un paradigma perdido en las políticas públicas mexicanas. Saarbrücken: Editorial Dictus.

Fuentes Díaz, Vicente. 1981. Valentín Gómez Farías: Padre de la Reforma. México D.F.: Gobierno de la República.

García Granados, Ricardo. 1906. La constitución de 1857 y las Leyes de Reforma: estudio histórico-sociológico. México D.F.: Tipografía Económica.

1909. El problema de la organización politica de México. México D.F.: Tipografía Económica.

González Navarro, Moisés. 1952. El pensamiento político de Lucas Alamán. México D.F.: El Colegio de México. . 1953. «Alamán e Hidalgo». Historia Mexicana. Vol. 3, núm. 2(10): 217-240.

Hale, Charles A. 1991. La transformación del liberalismo en México a fines del siglo XIX. México D.F.: Editorial Vuelta.

. 1994. El liberalismo mexicano en la época de mora (1821-1853). México D.F.: Siglo XXI Editores.

Humboldt, Alexander von. 2002. Ensayo político sobre el reino de la Nueva España. México D.F.: Editorial Porrúa.

Hutchinson, C. A. 1983. Valentín Gómez Farias. La vida de un republicano. Guadalajara: Gobierno del Estado de Jalisco.

Ibarra García, Laura. 2012. «Las ideas de Ignacio Ramírez, El Nigromante. Su significado en la historia del pensamiento mexicano». Iztapalapa Revista de Ciencias Sociales y Humanidades. Vol. 33, núm. 72: 153-178.

Iglesias, José María. 1893. Autobiografía del Sr. Lic. José María Iglesias. México D.F.: Antigua Imprenta de E. Murguía.

. 2003. El estudio de la historia. México D.F.: Universidad Nacional Autónoma de México y Fondo de Cultura Económica (FCE).

Lerdo de Tejada, Miguel. 1853. Comercio exterior de México desde la Conquista hasta hoy. México D.F.: Imprenta Rafael y Rafael.

Limantour, José Ives. 1965. Apuntes sobre mi vida pública. México D.F.: Porrúa.

López Portillo y Rojas, José. 1910. Ensayos económicos. México D.F.: Tipografía de El Tiempo.

Ludlow, Leonor. 2005. «La Comisión Monetaria Mexicana (1903)». El economista mexicano. Núm. 10: 38-79.

Marichal, Carlos. 1992. «Introducción». En: La Economía Mexicana: Siglos XIX y $X X$, Colección Lecturas de Historia Mexicana tomo 4, México, El Colegio de México, pp. VII-XXVI.

Molina Enríquez, Andrés. 1909. Los grandes problemas nacionales. México D.F.: Imprenta de A. Carranza e Hijos. 
Mora, José María Luis. 1837. Obras sueltas de José María Luis Mora. Tomo I. París: Librería de Rosa. . 1965. México y sus revoluciones. México D.F.: Editorial Porrúa. . 1994a. José María Luis Mora. Obras completas (Obra Política). Volumen II.

México D.F.: Instituto Mora y Conaculta. . 1994b. José María Luis Mora. Obras completas (Obra Política). Volumen III. México D.F.: Instituto Mora y Conaculta.

Nisbet, Robert. 1981. Historia de la idea de progreso. Barcelona: Editorial Gedisa. Potash, Robert A. 1953. «La fundación del Banco de Avío». Historia Mexicana. Vol. 3, núm. 2(10): 261-278. 1986. El Banco de Avio de México. El fomento de la industria 1821-1846. México D.F.: Fondo de Cultura Económica.

Pi-Suñer Llorens, Antonia. 1996. Historiografía mexicana. En busca de un discurso integrador de la nación, 1848-1884. Volumen IV. México D.F.: Universidades Nacional Autónoma de México.

Prieto, Guillermo. 1850. Indicaciones sobre el origen, vicisitudes y estado que guardan actualmente las rentas generales de la Federación Mexicana. México D.F.: Imprenta de Ignacio Cumplido.

. 1871. Lecciones elementales de economía política, dadas en la Escuela de Jurisprudencia de México en el curso de 1871. México D.F.: Imprenta del Gobierno. . 1888. Breves nociones de economía politica. México D.F.: Oficina Tipográfica de la Secretaría de Fomento.

. 1906. Memorias de mis tiempos (1840 a 1853). París/México: Librería de la Viuda de C. Bouret.

Ramírez, Ignacio «El Nigromante». 1889a. "Congreso Constituyente’. Discurso pronunciado en la sesión del 7 de Julio de 1856, al discutirse la Constitución en lo general». Obras de Ignacio Ramírez. Tomo I. México D.F.: Oficina Tipográfica de la Secretaría de Fomento, 187-194.

. 1889b. «La Constitución». Obras de Ignacio Ramírez. Tomo II. México D.F.:

Oficina Tipográfica de la Secretaría de Fomento, 285-290. . 1867b [1889c. «La apelación al pueblo (abril de 1867)». Obras de Ignacio Ramírez. Tomo II. México D.F.: Secretaría de Fomento, 297-302.

. 1889d. "Reformas civiles y criminales en favor de los desvalidos (7 de septiembre de 1871)». Obras de Ignacio Ramírez. Tomo II. México D.F.: Oficina Tipográfica de la Secretaría de Fomento, 377-388. . 1889e. «El trabajador y las fuerzas equivalentes». Obras de Ignacio Ramírez. Tomo I. México D.F.: Secretaría de Fomento, 309-314. . 1889f. «El trabajo (12 de noviembre de 1875)». Obras de Ignacio Ramírez. Tomo II. México D.F.: Secretaría de Fomento, 113-116.

Rejón, Manuel Crescencio. 1943. Discursos parlamentarios, 1822-1847. México D.F.: Secretaría de Educación Pública. 
Reyes Heroles, Jesús. 1974. El liberalismo mexicano. II. La sociedad fluctuante. México D.F.: Fondo de Cultura Económica. 1994. El liberalismo mexicano. III. La integración de las ideas. México D.F.: Fondo de Cultura Económica.

Riva Palacio, Vicente. 1888. México a través de los siglos (El Virreinato). Tomo II. México D.F./Barcelona: Ballesca y Compañía Editores y Espasa y Compañía Editores.

Romero Sotelo, María Eugenia. 2005. «La Reforma Monetaria de 1905. La Cuarta y Quinta Subcomisión: argumentos y propuestas». El economista mexicano. Núm. 10: 80-97.

Santos Valdés, José. 2002. Valentín Gómez Farías. México D.F.: Instituto Politécnico Nacional.

Sierra, Justo. 1940. Evolución politica del pueblo mexicano. México D.F.: La Casa de España en México. . 1977a. "Apología de la ciencia». Obras completas, volumen IV. Discursos. México D.F.: Universidad Nacional Autónoma de México. . 1977b. «El programa de La Libertad». Obras completas, volumen IV. Discursos. México D.F.: Universidad Nacional Autónoma de México. 1977c. «México social y político: apuntes para un libro». Obras completas, volumen IX. Ensayos y textos elementales de historia. México D.F.: Universidad Nacional Autónoma de México.

Spencer, Herbert. 1851. Social Statics: or, the conditions essential to human happinness specified, and the first of them developed. London: George Woodfall and Son. 1867. First principles. London: Williams and Norgate. . s/f. El individuo contra el Estado. Valencia: F. Sempere y Ca. Editores.

Torres, Victor Manuel. 1962. «El pensamiento político de Ignacio Ramírez». Historia Mexicana. Vol. 12, núm. 2(46): 190-228.

Woldenberg, José. 1996. Francisco Zarco. México D.F.: Ediciones Cal y Arena. Zarco, Francisco. 1857. Historia del Congreso extraordinario constituyente de 1856 y 1857. México D.F.: Imprenta de Ignacio Cumplido, 2t.

Zavala, Lorenzo de. 1834. Viage a los Estados Unidos del Norte de América. París: Imprenta de Decourchant.

Zea, Leopoldo. 1963. «El Positivismo». En Zea, Leopoldo. Estudios de historia de la filosofía en México, México D.F.: Universidad Nacional Autónoma de México. . 1968. El positivismo en México. Nacimiento, apogeo y decadencia. México D.F.: Fondo de Cultura Económica. 